\title{
Effects of Divorce on Children and Ways Schools Can Offer Support
}

Cheryl Ellington

Cedarville University

Follow this and additional works at: http://digitalcommons.cedarville.edu/education theses

Part of the Education Commons

\section{Recommended Citation}

Ellington, Cheryl, "Effects of Divorce on Children and Ways Schools Can Offer Support" (2003). Master of Education Research Theses.

2.

http://digitalcommons.cedarville.edu/education_theses/2 
EFFECTS OF DIVORCE ON CHILDREN

\title{
AND WAYS SCHOOLS CAN OFFER SUPPORT
}

\author{
A thesis submitted in partial fulfillment \\ of the requirements for the degree of \\ Masters of Education
}

By

\section{CHERYL ANN ELLINGTON}

B.A. Education, Cedarville University, 1980

2003

Cedarville University 


\section{CEDARVILLE UNIVERSITY \\ SCHOOL OF GRADUATE STUDIES}

May 10, 2003

I HEREBY RECOMMEND THAT THE THESIS PREPARED UNDER MY SUPERVISION BY Cheryl Ann Ellington ENTITLED Effects of Divorce on Children and Ways Schools Can Offer Support BE ACCEPTED IN PARTIAL FULFILLMENT OF THE REQUIREMENTS FOR THE DEGREE OF Master of Education.

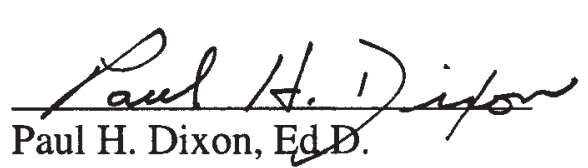

President

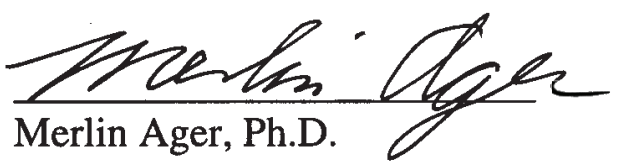

Dean, School of Social Sciences and Professional Studies

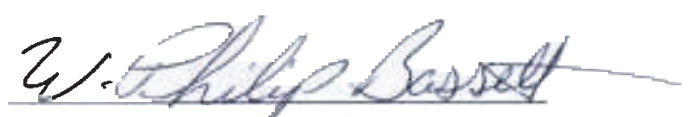

W. Philip Bassett, Ph.D.

Education Department Chair
Wuane K. Word Duane R. Wood, D.B.A. Academic Vice President

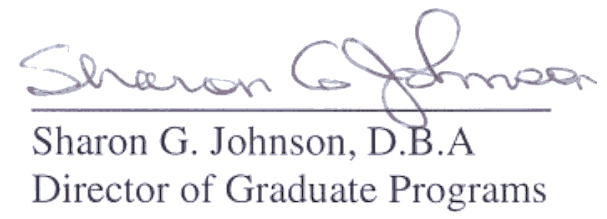

Director of Graduate Programs

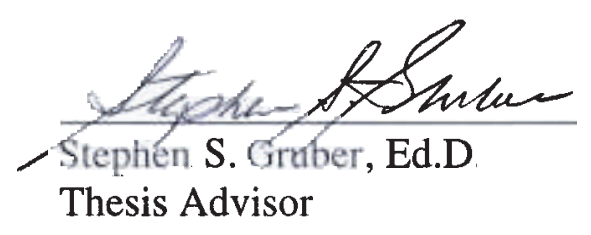




\begin{abstract}
Ellington, Cheryl Ann. M.Ed. Education Department, Cedarville University, 2003. Effects of Divorce on Children and Ways Schools Can Offer Support.

From 1990 to 1999, almost 15 million children in the United States experienced the divorce of their parents. Children experience varied effects from the divorce process, and they carry these effects with them into the classroom. By knowing what possible effects may occur, educators can be better equipped to effectively teach the children from divorced families who are in their care. It is the purpose of this thesis to explore both the possible effects of parental separation and divorce on children and to discover ways schools can provide support to help the children thrive. A unique characteristic of this study was its setting in a Christian school of approximately 700 students.
\end{abstract}




\section{TABLE OF CONTENTS}

CHAPTER I: Introduction Page

Educational Significance................................................

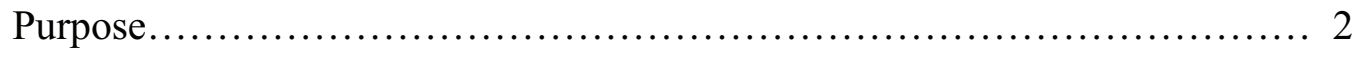

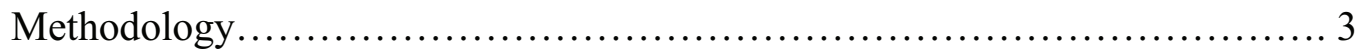

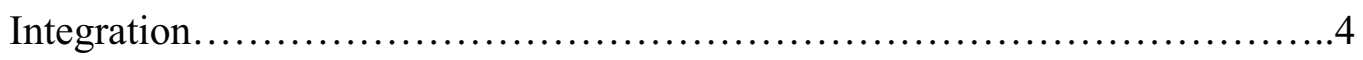

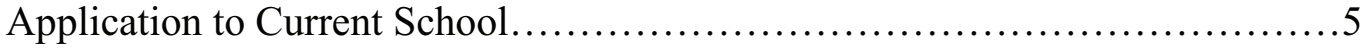

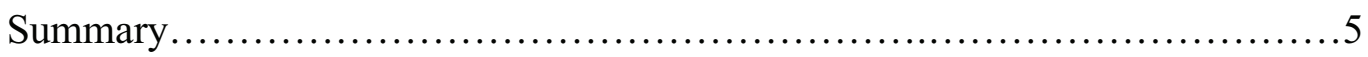

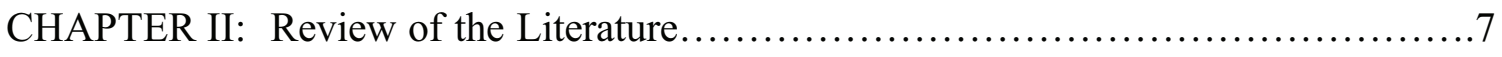

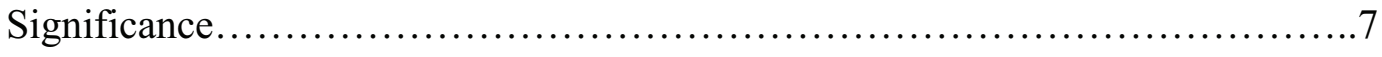

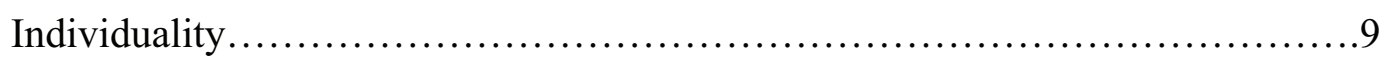

Factors......................................................................... 10

Economic Circumstances................................................ 10

Gender................................................................

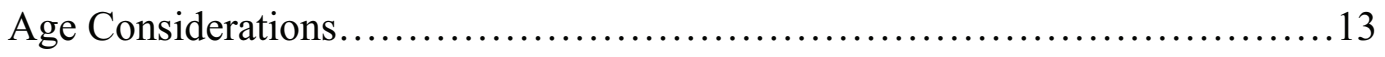

Preschool Children.................................................. 15

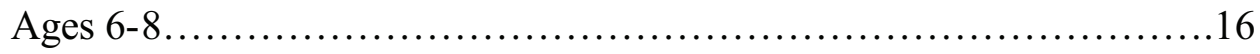

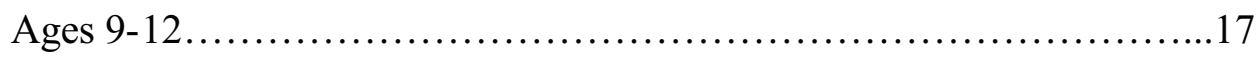

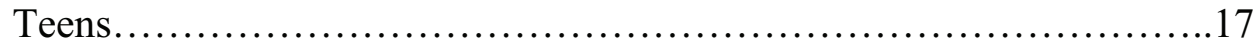

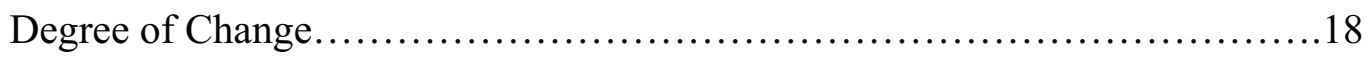

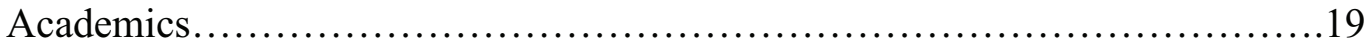




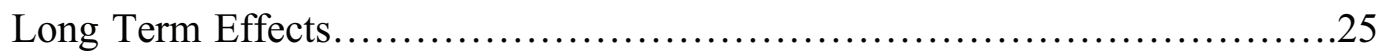

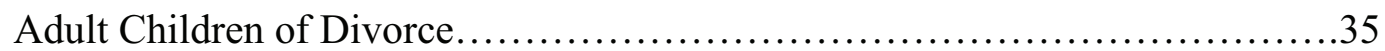

Ways Schools Can Offer Support............................................

Support Strategies from Miller........................................38

Support Strategies from Lipnickey .................................41

Support Strategies from Sammons \& Lewis............................43

Support Strategies from Diamond....................................43

Support Strategies from Brodkin.....................................44

Support Strategies from Barr........................................44

SchoolBased Intervention Programs .......................................45

Children of Divorce Intervention Program............................47

Support Strategies Directed Toward Parents................................50

Support Strategies from Benedek..................................50

Support Strategies from Wolf......................................53

Support Strategies from Neuman....................................53

CHAPTER III: Divorce Study in the Christian School...............................55

Permission from Administration and Executive School Board...................55

Enlisting Group Leaders from Teachers...................................57

Identifying Potential Participants.........................................58

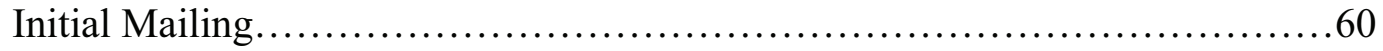

Cataloging Results of Responses........................................61

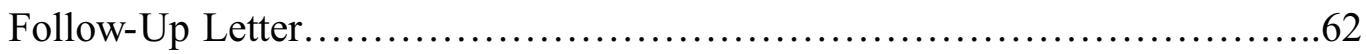


Summary of Responses....................................................

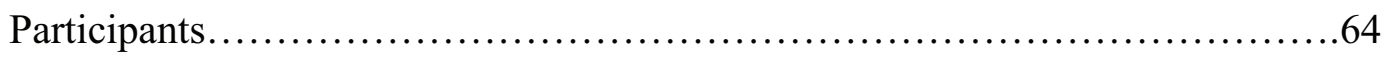

Measurement Tools.......................................................65

Metamorphosis of the Study..............................................66

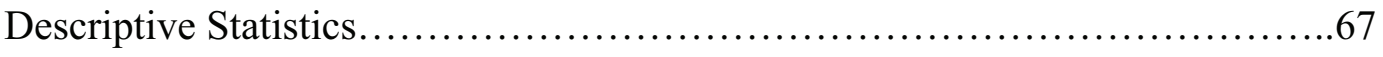

Initial Parental Input.........................................................

Initial Student Input............................................................ 75

Initial Teacher Input..................................................... 76

The Heart of the Project..................................................... 77

CHAPTER IV: Perspectives, Conclusions, and Recommendations.....................91

Perspectives and Conclusions of Teachers.................................99

Perspectives and Conclusions of Parents...................................99

Perspectives and Conclusions of Students................................. 98

Perspective and Conclusions of the Researcher.............................102

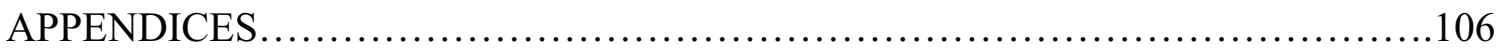

APPENDIX A: Teacher Release Form......................................106

APPENDIX B: Explanation to Executive School Board........................107

APPENDIX C: Initial Letter to Separated or Divorced Families................108

APPENDIX D: Permission Form for Children from Separated or

Divorced Families.......................................109

APPENDIX E: Initial Letter to Non-Separated or Non-Divorced Families......110

APPENDIX F: Permission Form for Children from Continuously Married

Two-Parent Families......................................111

APPENDIX G: Follow-Up Letter........................................112 
APPENDIX H: E-mail Enlisting Help from Teachers......................113

APPENDIX I: Contact Information for CODIP ...........................114

APPENDIX J: Researcher's Final Questionnaire for Students................115

APPENDIX K: Final Discussion Questions for Group.......................116

APPENDIX L: Final Teacher Questionnaire..................................118

APPENDIX M: Final Parent Questionnaire.................................119

APPENDIX N: Final Letter to Parents....................................... 120

APPENDIX O: Random Selection Letter................................121

APPENDIX P: Peer Group Letter........................................... 122

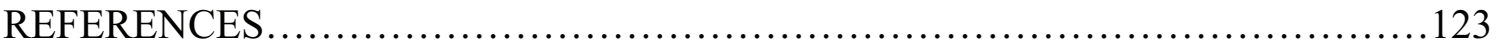

VITA........................................................................ 130 


\section{ACKNOWLEDGEMENTS}

Many individuals helped and encouraged me as I completed graduate school and tackled writing this thesis, and I owe them my gratitude.

I would like to thank all of my professors at Cedarville University for challenging me to continue to grow and improve as an educator.

Dr. Stephen Gruber, thank you for guiding me throughout the entire graduate school process and the writing of this thesis.

Dr. Merlin Ager, your encouragement and selfless investment in me during a time when the project required a comp lete redirection mean so much.

Dr. Ed Baumann, thank you for allowing me to first explore the topic for this thesis in your Social Diversities class.

To my teaching colleagues, Craig and Celeste Dunlap, you two are terrific! The graduate school process was so much more enjoyable with your company. Thanks for the long drives together for classes at Cedarville University and for the study sessions we had. Your continued interest and support as I wrote my thesis encouraged me to stay on target.

To Jeff Bowers, thanks for the tutoring and listening sessions as we drove together the final summer of classes.

To my principal, Mr. Rick Schrenker, thank you for your willingness and expertise in proofreading my thesis. To quote an encouragement you often give to your teachers, "You mean more than you'll ever know."

To my administrator, Mr. Don James, thanks for the encouragement to pursue graduate school and for permission to use Calvary Christian School as the basis of my thesis.

To the students from Calvary Christian School who participated in the peer support group sessions with me, I love you. Thank you for allowing me to learn from you.

To my colleagues Stephanie Owens, Joyce McQueen, and Michelle O’Dwyer, thank you for assisting me in leading the peer support groups.

To my student helper, Kelli Summers, thanks for preparing mailings, stamping endless envelopes with "confidential," and cheerfully doing whatever I asked of you.

To my sons, Matt and Jon, thanks, guys. You had to assume additional responsibilities with mom gone during summers and working on projects when at home. You didn't complain and always encouraged me with comments like, "You can do this, Mom!" I love you both. 
To my parents, Verne and Kathryn Sprunger, I love you and owe you so much. Thanks for leading me to Jesus Christ and for modeling what it means to love the Lord and each other. You have been a constant source of encouragement and strength for me.

To my in-laws, Charles and JoMae Ellington, I'm so thankful that you have modeled for Dave what my parents have modeled for me. Thank you for your endless encouragement and love.

To my Savior, Jesus Christ, thank You for bringing all of these special people into my life, for giving me salvation, and for lovingly directing everything You ask me to do. 


\section{DEDICATION}

I am dedicating this thesis to my best friend and husband, Dave Ellington. He has completely supported me throughout graduate school and has urged me to continue learning. He models complete trust in the Lord and complete dedication to serving Him.

Dave, you really are my inspiration. I love you. 
Chapter I: Introduction

\section{Educational Significance}

From 1990 to 1999, almost 15 million children in the United States experienced the divorce of their parents (Sammons, 2000, p.64). By the time students in the United States reach the age of eighteen, $50-60 \%$ of them will be affected by divorce (Miller, 1999, p.285). Fifty percent of all children who have experienced their own parents' divorce will experience a second divorce by the age of sixteen if their mother remarries (Levine, 1995, p.10). Children experience varied effects from the divorce process, and they carry these effects with them to the classroom. By knowing what to expect, educators will be better equipped to effectively teach the children of divorce who are in their care (Benedek, 1998, p.61). In this study, the term "children of divorce" refers to children whose parents have divorced and who are living with only one biological parent at any given time. The research questions examined by this study include the following: What are the possible effects of divorce on a child and his educational experience? In what ways can schools provide positive educational experiences that will support children of divorce?

A wide spectrum exists in the possible effects divorce may have on children and their educational experiences. Because of the prevalence of divorce in society, "every teacher needs to be familiar with the effects divorce may have on a child's classroom 
behavior" (Miller, 1999, p.285). Developmental pediatricians and authors William Sammons and Jennifer Lewis state that they have seen many who have successfully coped with divorce, and they frequently attribute the success to the "unheralded support of teachers and schools" (Sammons, 2000, p.64). Paul Miller, Associate Professor in the Department of Social \& Behavior Sciences at Arizona State University West, elaborates what exactly constitutes this support. "Effective teaching of children of divorce requires an understanding of the impact of divorce, a supportive environment, safe channels for children to communicate feelings and problems, instruction on building coping and self regulation skills, and resources to help parents" (Miller, 1999, p.285). Following a scrutiny of twenty-five teacher training programs that mentioned divorce, Miller further discloses that none prioritized the topic among training objectives (Miller, 1999, p.285). He concludes that teachers will need to take the initiative for additional study. The purpose of this current research is to accomplish that goal. In reference to children of divorce, Susan Lipnickey, Associate Professor of Physical Education, Health and Sport Studies at Miami University in Oxford, Ohio, summarizes that educators have the opportunity to "make a major difference in children's lives and let them focus on what's most important - learning" (Lipnickey, 2001, p.55).

\section{Purpose}

The majority of research available pertains to unidentified school systems. Because the researcher is immersed in a Christian school setting, the purpose was to examine and apply appropriate discoveries regarding the effects of divorce on educational experiences of children and ways to support them in the Christian school. 


\section{Methodology}

The research study commenced with the exploration of the diverse information pertinent to the effects of divorce on children and their educational experiences found within journal articles, scholarly papers and books. From this conglomerate, an analysis

and synthesis of the best evidence was formed (Slavin, 1986, p.6). The definite direction the study would take was dependent upon four following factors:

1. Evidence provided by the analysis and synthesis of the available literature

2. Administrative permission and guidance

3. Available population within the school

4. Willingness of divorced parents to allow the researcher to involve them and their children.

The first two factors encouraged the study to continue. The latter two factors, however, produced roadblocks. The original intent of the researcher was to complete a quantitative study involving a sample of no less than 20 children from separated or divorced homes in a Christian school in Northern Kentucky. The school contained a small proportion of children from divorced homes compared to children from continuously married twoparent homes. In addition, approximately $2 / 3$ of the divorced families were unwilling to allow their children to be included in a thesis study. The reality became a sample size of ten incapable of making inferences to any general population. Following the counsel of graduate advisors, the character of the study changed from quantitative to qualitative in nature. The most significant advantage in this shift was the ability of the researcher to now become personally involved with the group of ten and to learn about feelings and 
challenges of children of divorce directly from them. Four groups of stakeholders were involved in the project: teachers, parents, students, and the researchers. Perspectives of each group are included in the thesis. A control group of students from continuously married two-parent homes was included for comparison. Teachers, parents, and the children completed open-ended questionnaires and ratings. The researcher conducted both individual and group interviews with the children. The heart of the study consisted of eleven weekly peer-support group sessions involving the researcher and six students in fourth-sixth grades. Attendance, academic records, and Stanford Achievement Test scores of both the experimental and control groups were reviewed and compared. The information gained from the study and the participants was invaluable in assisting the researcher to better understand challenges children from divorced homes must meet. The goal of the thesis was to discover in what ways the divorce process affects the children and what components are necessary to enable children of divorce to thrive in the Christian school. The students themselves provided the answers.

\section{Integration}

Had it not been for The Fall as explained in Genesis 3, children of divorce would not be a current topic in Christian education. When sin entered Eden, the long-lasting relationship of marriage described in Genesis 2:24 contained the potential to be damaged. When this occurs, the additional characteristics of God's grace, love, redemption, and hope are essential elements in the healing process. God places the responsibility of educating children on the parents (Deuteronomy 4:11; Deuteronomy 11:18-21; Proverbs 22:6). This enormous responsibility becomes more difficult when parents are not unified 
in the effort. Some parents may unwillingly find themselves in the role of single parenting. Whatever the circumstances, Christian educators can offer support to parents and children in the educational process. Together, educators and parents can enable the children of divorce to view themselves as God sees them: valuable children specially designed in His image.

\section{Application to Current School}

Following the analysis and synthesis of the best evidence (Slavin, 1986, p.6), information was examined for both its correlation with the Bible and its relevance to the Christian school. The Children of Divorce Intervention Program (CODIP) developed by Pedro-Carroll was replicated in a northern Kentucky Christian school. The goal was to understand ways students may be affected by divorce and to discover ways Christian educators can help these students thrive in the Christian school setting. If Christian educators begin to learn how to accomplish these goals, perhaps the benefits can be extended to similar schools.

\section{Summary}

With the prevalence of divorce in society and the vast number of children affected by the process of divorce, it has become necessary for educators to address related issues in education. Knowing both potential behaviors and effective ways to respond to the behaviors that support children of divorce in their learning experiences is beneficial. Christian schools are not immune to the effects of divorce, and studies directed to 
Christian schools are lacking. It is the goal of this researcher to examine possible effects of divorce on children and to make recommendations for the Christian school setting. 
Chapter II: Review of the Literature

\section{Significance}

A review of the literature reveals the pervasiveness of divorce and the resulting children affected by divorce in American society. Consider the following evidence. Divorce has become the norm for American society (Fassel, 1991, p.4), and the United States has the highest divorce rate in the industrialized world (Manning, 1991, p.13). Statistics show that more than one million children each year become children of divorce (Amato, 2001, p.355; Belli, 1988, p.198; Hetherington, 1998. p.167; Teyber, 2001, p.4). One of every two marriages in the United States is expected to end in divorce (Levine, 1995, p.10). Barna's research contests the figure of 50\% ending in divorce as too high and states that $27 \%$ of individuals claiming to be "born-again Christians" experience divorce while $24 \%$ of individuals not claiming to be "born-again Christians" become divorced (Barna, 1999, p.9). Over sixty percent of the couples seeking divorce have children at home (McKay, 1999, p.187). Sixty percent of all children born in the 1990's will experience the divorce of their parents by age sixteen (Fassel, 1991, p.4; Levine, 1995, p.10; Miller, 1999, p.285). In the 1990's, fifteen million children under the age of eight experienced the divorce of their parents (Sammons, 2000, p.65). Thirty-seven percent of all children with a remarried parent experience a second divorce (Emery, 1999, p.19), and fifty percent of all children whose mothers remarry experience a second divorce by age sixteen (Fassel, 1991, p.4; Levine, 1995, p.10). To summarize, for more than half of all American children, divorce is a fact of life (Neuman, 1998, p.4). When 
applying these facts to school situations, in most American classrooms, one-third to onehalf of the children live in a family of divorce or remarriage (Ahrons, 1994, p.41).

While much debate exists about the possible long-term effects of divorce on children, the literature agrees about the initial impact. Author Melvin Belli states, "The consequences of a divorce are the equivalent of a major earthquake in a child's mind and feelings" (Belli, 1988, p.213). Children of divorce can become "consumed by fear of the unknown" (Benedek, 1998, p.60). Other sources describe divorce as "periods of unparalleled stress and psychological pain for children" (McKay, 1999, p.187), "a new place of emptiness because the way it used to be isn't anymore" (Wolf, 1998, p.50) and "only slightly less traumatic for children than the death of a parent" (Hart, 1996, p.19; Lansky, 2000, p.29). Lansky further explains that in death, mourning is accepted and encouraged. Friends and relatives are usually available to console the children. In divorce, however, the support of family and parents is many times unavailable to the children (Lansky, 2000, p.27). Hargreaves agrees that death is final and has closure, but divorce is never "over" for a child (Hargreaves, 1991, p.6). While divorce is stressful for parents, it is even more stressful for children (Hetherington, 2002, p.122; Lansky, 2000, p.1). "Divorce can be the most devastating experience of a child's life because it disrupts his developing sense of trust, security, and self, and where they fit into the family and other groups" (Weyburne, 1999, p.2). In the introduction to his book

psychotherapist Dr. Archibald Hart shares the following personal insight: "My parents divorced when I was twelve. That singular event changed my life forever" (Hart, 1996, p.xi). Dr. Gary Neuman echoes with the comment, 
"Even in the best of situations, divorce can endure as the defining moment of a child's life" (Neuman, 1998, p.5). Dr. Mavis Hetherington, a strong advocate for generally positive long-term outcomes for children of divorce, asserts, "For a young child, divorce is the equivalent of lifting a hundred pound weight over the head. Processing all the radical and unprecedented changes stretches immature cognitive and emotional abilities to the absolute limit and sometimes beyond that limit. The very bedrock of the child's well-being is shattered" (Hetherington, 2002, p.112).

\section{Individuality}

Children are individuals. They will exhibit a variety of reactions in divorce situations (Benedek, 1998, p.61). Hetherington identifies “great diversity in children's responses to parental marital transitions" (Hetherington, 1998, p.68). In addressing individuality, she encourages, "Be suspicious of averages and focus on diversity" (Hetherington, 2002, p.275). Amato, a researcher who performed multiple meta-analyses on past and current studies of children of divorce, supports individuality with the claim that "knowledge of group averages cannot predict how a particular child will adjust to family disruption" (Amato, 2001, p.366). Miller agrees that children's responses are not uniform but that they do follow patterns (Miller, 1999, p.286). Wallerstein comments that children respond according to "their own internal timetables" rather than conforming to a defined pattern (Wallerstein, 1980, p.268). Lansky asserts that the child's reaction will largely be determined by the parental reactions (Lansky, 2000, p.31). While the effects will vary, Rhonda Freeman, President of "Families in Transition" in Toronto, Canada, 
states, "In twenty-five years, I have yet to meet a child who has no effects" (Driedger, 1998, p.39).

\section{Factors}

Many factors intertwine to influence how divorce affects a particular child. Economic circumstances, gender, age at time of divorce, personality, coping skills, nature of family, degree of access to both parents, amount of change, presence of a third party, degree of hostility expressed, and downward social mobility compose the complicated web of contributing factors (Craig, 1991, p.374; Hetherington, 1998, p.178; Lansky, 1989, p.31; Levine, 1995, p.91; McKay, 1999, p.191; Miller, 1999, p.286; Wolf, 1998, p.55). Authors differ in the degree of importance placed upon each component.

\section{Economic Circumstances}

"One of the best kept secrets about divorce is the economic impact it has on families" (Levine, 1995, p.4). The Sun and Li Study conducted over a period of six years gives general support that negative impact of divorce can be largely attributed to economic hardship (Sun, 2002, p.486). Financial pressures increase following divorce (Engel, 1992, p.26; Wolf, 1998, p.55). Expenses expand with the addition of a second household. Emery states that the most notable change following divorce is a drop in standard of living - especially for divorced women and custodial children (Emery, 1999, p.81). While it is generally agreed that an economic decline for women and children exists, the degree of decline is disputed (Ahrons, 1994, p.94). What is not disputed is the fact that ninety percent of the children of divorce live with their mothers (Fassel, 1991, 
p.107; Levine, 1995, p.26; Thompson, 1999, p.6), and so the children also experience the economic decline. Assertions regarding the level of decline follow. One study shows that immediately following divorce, women experience a 73\% drop in their standard of living while men experience a $42 \%$ raise in standard of living (Levine, 1995, p.41). A second study from the University of Michigan contests these figures as too extreme and shows a $30 \%$ drop for women and a 10-15\% increase for men. (Levine, 1995, p.41). Based on national data from the Michigan Panel Study of Income Dynamics, in one year after divorce, women's income dropped to $91 \%$ of their needs, and men's income rose to $113 \%$ of their needs. Five years later, the $91 \%$ for the women was stationary while the men's percentage rose to $130 \%$ (Emery, 1999, p.81). In 1994, 37.6\% of children living with divorced mothers were in poverty (Thompson, 1999, p.8). For mothers and children, living standards fall by $10 \%$ in the year after divorce and then remain stationary (Thompson, 1999, p.8). The Virginia Longitudinal Study conducted by Mavis Hetherington yielded slightly different results in that both men and women experienced an economic decline. The decline for men was $10 \%$ while the decline for women was $30 \%$. In her study, many middle-class women fell into poverty after divorce. One year after the divorce, the single mothers and children had "a little less than half the income of the non-divorced families in the study" (Hetherington, 2002, p.48). While the level of decline is debatable, the fact remains that children experience a lower standard of living following divorce. 


\section{Gender}

In consideration of gender, reports are contradictory. The most prevalent view purports that girls experience less difficulties in adjustment than do boys. McKay asserts that girls usually adjust more quickly to divorce (McKay, 1999, p.191). He suggests that a possible explanation is more sensitive consideration shown to the girls by the parents (McKay, 1999, p.191). He further explains that boys sense rejection by their fathers and lose their role model and identification (McKay, 1999, p.188). Boys may need more assistance in expressing their emotions due to restrictions society generally places on males (McKay, 1999, p.188). Benedek agrees that boys may need extra encouragement to express sadness because society gives the message of weakness for males to display related emotions (Benedek, 1998, p.63). Lansky states that boys experience more grief and sadness than do girls their age and that divorce has a more lasting impact on boys (Lansky, 2000, p.54). While sadness may be suppressed, boys tend to express more anger and aggression than do girls (Benedek, 1998, p.62; Lansky, 2000, p.54). When the anger and aggression are manifested in the school setting, complications in other schoolrelated areas may develop (Lansky, 2000, p.54; Teyber, 2001, p.14). Teyber identifies more adjustment, behavior, and academic problems in boys than in girls (Teyber, 2001, p.14). Difficulties can be reduced to the level of boys from non-divorced homes if the noncustodial father maintains contact with the son (Lansky, 2000, p.54). In contrast, Teyber has found that two years following a divorce, girls from divorced families are as welladjusted as girls from non-divorced homes, but an "increasingly widening gap in problematic behavior" exists between boys from divorced families and boys from nondivorced homes (Teyber, 2001, p.14). Girls exhibit more eating problems such as 
anorexia or bulimia related to divorce than do boys (Benedek, 1998, p.72). Benedek states that the initial overt reactions from the divorce should recede in six months to one year for a girl and one and one-half years to two years for a boy (Benedek, 1998, p.83). The Wallerstein study supports the finding that girls are better adjusted than boys at eighteen months following divorce (McKay, 1999, p.191). The Guidubaldi study from Kent State University found that girls consistently demonstrated better adjustment than boys in areas ranging from social skills to school grades (Lansky, 2000, p.49). The 1997 Grych and Fincham study reports that by adolescence, adjustment levels are equitable between boys and girls (Miller, 1999, p.285). Hetherington cautions that gender differences are "less pronounced and less consistent than previously believed" (Hetherington, 1998, p.171). The Sun and Li study found little evidence for gender differences. They offer the high school age limit for their study as a possible explanation for lack of differences in gender (Sun, 2002, p.486). Amato's 2001 meta-analysis provides "modest" support that divorce has stronger effects on boys than girls only in the domain of social adjustment (Amato, 2001, p.361). The central finding of the metaanalysis is that "divorce is associated with a range of poor outcomes among children irrespective of gender" (Amato, 2001, p.361) and that "most of the disadvantages associated with divorce are similar for boys and girls (Amato, 2001, p.365).

\section{Age Considerations}

Regardless of a child's age, the number one concern of any child is "What is going to happen to me?" (Engel, 1992, p.26; Wallerstein, 1980, p.35). The question, “At what age will divorce have the least damaging effects?" is often raised. Wolf responds, 
"There is no best age" (Wolf, 1998, p.29). For many children, the biggest concern that the initial break-up brings is the fear of losing their parents (Teyber, 2001, p.31). In general, younger pre-school children seem less troubled than older children (Engel, 1992, p.24). Typically, elementary age children will experience complications in the area of social adjustment while complications for high school age are related more to selfconcept (Miller, 1999, p.286). Many of the child's concerns and responses are dependent upon his cognitive and emotional development (Miller, 1999, p.286). If there are dramatic "age-at-separation" effects, they have not been demonstrated empirically (Emery, 1999, p.59). Potential negative reactions for any age include fear, sadness, grief, anger, hostility, guilt, loneliness, resentment, shock, confusion, rejection, regression, depression, anxiety, exaggerated responsibility, sleep problems, masturbation, school problems, physical problems, and eating problems (Belli, 1988, p.216; Benedek, 1998, p.61-71; Berry, 1998, p.73; Engel, 1992, p.23; Fassel, 1991, p.3; Lansky, 2000, p.30; Levine, 1995, p.17; McKay, 1999, p.187; Miller, 1999, p.286; Wolf, 1998, p.17). Weyburne identifies children's stages of grief as shock, denial, anger, sadness or depression, and healing (Weyburne, 1999, p.72-76). Hart identifies stages of feelings as fear and anxiety, abandonment and rejection, aloneness and sadness, frustration and anger, rejection and resentment, re-establishment of trust (Hart, 1996, p.67). Benedek states that all children express fear with divorce. Their age determines the object of that fear (Benedek, 1998, p.61). "Kids don’t want divorce” (McKay, 1999, p.187). A commonality among all ages is the intense desire for reconciliation (McKay, 1999, p.187; Wolf, 1998, p.37; Teyber, 2001, p.55). A second commonality among all ages is the view that the divorce is something happening to them personally (Berry, 1998, p.73). 


\section{Pre-school Children}

Preschoolers under the age of two years are not very aware of divorce and may seem less troubled than older children (Engel, 1992, p.24; Wolf, 1998, p.31). Effects may show up much later with these children. Children between the ages of birth and five years remember very little about the divorce but may have a pervasive feeling of anxiety (Fassel, 1991, p.47). Other theories suggest that divorce is most harmful for children under the age of five or six because of their limited ability to understand what is happening, and at the same time, divorce is most common in this age range (Emery, 1999, p.59). The major issues for older preschoolers are change and loss (Wolf, 1998, p.30). They fear abandonment and may become generally clinging and particularly anxious at bedtime. A preschooler's behavior may become regressive, and somatic symptoms are common (Benedek, 1998, p.61; Engel, 1992, p.24; Fassel, 1991, p.47; McKay, 1999, p.190; Miller, 1999, p.286; Teyber, 2001, p.11; Wallerstein, 1980, p.63;

Wolf, 1998, p.31). Routine can help preschoolers deal with divorce (Fassel, 1991, p.47; McKay, 1999, p.190; Miller, 1999, p.286; Wolf, 1998, p.31). Teaching a child to verbalize his feelings and to describe the object of his fear may help to alleviate uncertainty (Benedek, 1998, p.62; McKay, 1999, p.190). Role-play may be an effective tool (Benedek, 1998, p.77). Reassurance, consistency, and availability of parental support are necessary for preschoolers experiencing divorce (Benedek, 1998, p.62; Miller, 1999, p.286). 


\section{Ages 6-8}

Children from ages six to eight experience the most intense sadness of any age (Miller, 1999, p.286; Neuman, 1998, p.124; Teyber, 2001, p.11; Wallerstein, 1980, p.65). Benedek quotes a child expressing feelings of rejection, "I don't fit in anywhere. I feel like my insides are missing" (Benedek, 1998, p.68). Numbness is common, and children may intensely miss their father (Fassel, 1991, p.49; McKay, 1999, p.190). This age tends to worry about being left without a family and to worry about physical needs (Engel, 1992, p.24; McKay, 1999, p.190). Concerns about the welfare of their parents as well as economic insecurity are prevalent (Fassel, 1991, p.50; Wolf, 1998, p.33). An unrealistic hope that their parents will get back together captivates their thoughts (Lansky, 2000, p.38; Miller, 1999, p.287). Children in this age group often experience guilt because they believe the divorce was their fault (Fassel, 1991, p.51). Worries may be manifested by sleep difficulties, stomachaches, headaches, and nervous habits (Benedek, 1998, p.68; Lansky, 2000, p.38; Weyburne, 1999, p.97). School performance may decline (Wolf, 1998, p.33). Fantasy is often used as an escape (Benedek, 1998, p.79; Wolf, 1998, p.33). Children from ages six to eight are concrete in their thinking and "black and white" in their judgments. Concrete answers are needed in response to their literal questions (Benedek, 1998, p.79; Fassel, 1991, p.49). They need permission to express their sadness and reassurance that they are not the cause of the divorce (Benedek, 1998, p.62, 66). The permanence of the divorce and the inability of the child to do anything to reconcile the family must be emphasized (Benedek, 1998, p.66). Routine and reassurance are paramount in the coping of ages six to eight (Benedek, 1998, p.66). 


\section{Ages 9-12}

Divorce is frequently most difficult on children ages 9-12 (McKay, 1999, p.188; Weyburne, 1999, p.99). The predominant response for this age group is anger (McKay, 1999, p.190; Neuman, 1998, p.142; Teyber, 2001, p.12; Wallerstein, 1980, p.74). At times, the anger is explosive (Wolf, 1998, p.34). Often the anger is directed at the custodial parent (Fassel, 1991, p.51) or the parent who seems to the child responsible for the divorce (McKay, 1999, p.190). Permitting the child to express anger in acceptable ways is advised (Benedek, 1998, p.64). Physical activity is one possible outlet for anger (Benedek, 1998, p.64). Many times, this age group is caught between feuding parents (Wolf, 1998, p.33) and is more likely to be used as a confidant for a parent (Benedek, 1998, p.83). Children between ages 9-12 are likely to join a strong alliance against one parent (McKay, 1999, p.190). Guilt and grief are common responses (McKay, 1999, p.190; Miller, 1999, p.287). Their fear is directed toward financial needs (Benedek, 1998, p.83). Role models are particularly important for this age group (Benedek, 1998, p.82). Hart cautions that the spiritual development of a child is most likely to be damaged at this age. He explains that disappointment, disillusionment, and rejection of the parents' spiritual values could easily occur (Hart, 1996, p.21).

\section{Teens}

Teens fear how the divorce will change their lives (Benedek, 1998, p.83). They gravitate between fear and numbness (Fassel, 1991, p.51). Teens experience heightened emotions (Engel, 1992, p.25) and tend to be angrier than younger children. The anger is especially directed toward parents' dating. Many teens experience a deep sense of loss 
and emptiness (McKay, 1999, p.190). Feelings of betrayal may characterize teens (Teyber, 2001, p.13). Chronic fatigue, nightmares, diminished concentration, depression, and lack of interest in school are common (Wolf, 1998, p.34). Forced independence and an "exaggerated sense of adult responsibility" (Engel, 1992, p.25) are characteristics. Teens question whether or not their parents' divorce foreshadows failure in their own future relationship (McKay, 1999, p.190). In response, some withdraw (Engel, 1992, p.25). Others "translate unhappiness into bad adult behavior" such as sexual promiscuity, perversion, and/or drug or alcohol abuse (Belli, 1988, p.228; Fassel, 1991, p.51; McKay, 1999, p.190). Other escapes include food, shoplifting, running away, and suicide (McKay, 1999, p.190; Wolf, 1998, p.37). Some teens will use the divorce as a "catalyst for growing up" (McKay, 1999, p.190; Wolf, 1998, p.37). Adolescents who cope best have demonstrated moral courage, reasonable behavior, and good relationships with one or both parents (Engel, 1992, p.25). Teen children of divorce may positively maintain rapport with a teacher or other adult they like, and the relationship can strengthen the teen (Engel, 1992, p.25).

\section{Degree of Change}

"If one thing characterizes divorce, it is change" (Emery, 1999, p.1). The greater the amount of change a child experiences due to divorce, the greater will be the effects on the child (Wolf, 1998, p.55). Examples of change include economics, different housing, a new school, new friends, little access to the non-custodial parent, less time with the custodial parent, the introduction of a new dating partner, a pet left behind, and others (Wolf, 1998, p.55). Any combination of these factors of change increases the potential 
negative effects. The most notable change is a drop in the standard of living especially for divorced women and custodial children (Emery, 1999, p.81). Often the actual circumstances of the child's life will change for the worse, and "downward social mobility" will occur. Jonsson defines social mobility as "household changes in social class or occupational prestige and level of education" (Jonsson, 1997, p.277). If the parent with the higher education and social position leaves, the child will experience a downward social mobility which may lessen the educational aspirations and may diminish parental educational resources for the child (Jonsson, 1997, p.277).

\section{Academics}

"Family revolution is the greatest single cause of decline in academic achievement during the last twenty years. It's not better teachers, texts or curricula that our children need most. It's better childhoods" (Zinsmeister, 1996, p.42). Does divorce affect the academic achievement of children? Hargreaves states, "If an academic achievement gap exists between one-parent and two-parent children, the ramifications for educators are enormous" (Hargreaves, 1991, p.1). Declining school performance is common during the process of divorce (Benedek, 1998, p.10). Children from divorced families are more likely to perform less well academically, have a lower academic selfconcept, and are less motivated to achieve (Miller, 1999, p.285). Different studies have reached conflicting conclusions. In measuring academic competence, Emery has found statistical significance in four types of academic outcomes in children from divorced homes: lower standardized test scores, lower grades and related indicators of performance in school, various measures of misconduct in school, and school completion and 
educational attainment (Emery, 1999, p.45). A study by Teresa Peck, clinical psychologist at Center for Families in Transition, found a correlation between poor grades and divorce. She examined grades of students when they were in elementary school and again when they were in high school. She defines "underachievers" as students with A's and B's in elementary school who earn grades of D's and F's in high schools. Her definition of "achievers" is students who maintain A's and B's throughout elementary and high school. $78 \%$ of the underachievers were from divorced homes, while $30 \%$ of the achievers were from divorced homes (Emery, 1999, p.46). Wadsby and Svedin's well-known and often-quoted study on academic achievement included 221 children: 74 children from divorced homes, and 147 children from two-parent homes. The results demonstrated no significant difference between the two groups academically (Wadsby, 1996, p.326). Numerous international studies report academic aptitude and achievement to be inferior in children of divorce when compared to children of intact families. A 1992 study in Finland and a 1985 Wisconsin study both conclude that deterioration in school performance is one of the most consistent outcomes of divorce (Wadsby, 1996, p.326). The Hammond study of 1979 and the Watts study of 1991 both claim there is no difference in academic achievement (Wadsby, 1996, p.326). The Bisnaire study of 1991 reports significant decline in children of divorce but maintains they are well above failing (Wadsby, 1996, p.326). Kagan established in 1980 that socioeconomic status is associated with intellectual and academic functioning (Wadsby, 1996, p.326). The Swanum study of 1982 tested this theory in relation to divorced families and concluded that if socioeconomic status is controlled, no decline is found in the academic achievement of children of divorce (Wadsby, 1996, p.326). In contrast, the 
Guidubaldi study of 1983 concluded that divorce accounts for negative academic effect independent of income, educational and occupational levels of parents (Wadsby, 1996, p.326). In examining divorce-related socioeconomic status in addition to social mobility and academic effects, Jonsson's 1996 Swedish study concluded that downward social mobility has the greater negative effects on academics. Jonsson's study considered final grade point average. It also found no significant relationship between socioeconomic status and grade point average in children of divorce. Jonsson concludes that while psychological reactions in children of divorce will be the same internationally, economic conditions vary greatly among nations due to differences in labor-market opportunities, taxation, child support laws, and welfare. He recommends international studies that consider each of these areas while studying academic effects of divorce on children (Jonsson, 1997, p.277). Biblarz conducted a study comparing children of divorce with children of widowed mothers. His findings conclude that children of divorce were less likely to complete high school, attend college, or attend graduate school than children of widowed mothers. He attributes this to socioeconomic levels and financial stress placed on divorced mothers (Biblarz, 2000, p.535). The McLanahan and Sandefur Study of 1994 found that children from divorced homes were two times as likely to drop out of high school as children from two-parent homes (Emery, 1999, p.36). The 1988 University of Illinois Study by Sheila Krein concluded that boys in single parent homes are likely to get 1.7 fewer years of education than boys from two-parent homes (Lansky, 2000, p.55). The Virginia Longitudinal Study conducted by Hetherington found that children of divorce were more likely to have academic problems and experienced an increased rate of high school drop-out (Hetherington, 1998, p.169). Following high 
school, children from divorced homes are less likely to attend college than children from two-parent homes (Fassel, 1991, p.105; Gose, 1996, p.35; Levine, 1995, p.35). "The longer you live in a single-parent home, the less likely you are to go to college" (Gose, 1996, p.35). Financial concerns hinder college attendance. While a divorced father may be financially capable of assisting a child with college expenses, he may choose not to do so. The father's income is still considered in the child's process of seeking financial aid and many times eliminates the financial qualifications of the child to receive any financial aid (Gose, 1996, p.35; Levine, 1995, p.45). The longitudinal study conducted by Wallerstein determined negative correlation between divorce and school attendance, academic achievement, attitudes toward learning, and the ability to concentrate (Wallerstein, 1980, p.265). Wallerstein warns that "temporary interruptions in the learning process have the potential for becoming consolidated into significant academic problems if a child is not able to resume his learning efforts within a reasonable period of time" (Wallerstein, 1980, p.264). One year following the divorce, 55\% had good to excellent grades, and $25 \%$ had a steady decline in academic performance (Wallerstein, 1980, p.271). Five years following the divorce, the academic performance of the entire group was roughly comparable to levels at the time of the divorce. $40 \%$ produced academic work below average grade level. Limited intellectual capability was not a factor. The study also found that academic performance was not significantly related to the father or mother's socioeconomic level (Wallerstein, 1980, p.282). Wallerstein concludes that the divorce did not significantly alter school performance of the group as a group, but individual effects exist (Wallerstein, 1980, p.279). When examining the same group of children ten years later, Wallerstein found that $60 \%$ were on a downward 
education course when compared with their fathers, and $45 \%$ were on a similarly downward course compared with their mothers' level of education (Wallerstein, 1990, p.157).

Other factors related to academic achievement are common in children from divorced families. Many experience difficulty concentrating and exhibit restlessness (Benedek, 1998, p.60; Lansky, 2000, p.43; Wallerstein, 1980, p.264). Schoolwork may deteriorate because children are distracted with worry (Lansky, 2000, p.43; Richmond, 1998, p.33). Some children perform better in school as an attempt to shut out problems at home (Lansky, 2000, p. 43). In contrast, other children may intentionally allow grades to slip in an attempt to gain attention from both parents (Lansky, 2000, p.43; Richmond, 1998, p.33). Children living with newly divorced mothers are more likely to be late for school and are less likely to have help with their homework (Hetherington, 2002, p.46). "Growth-enhancing experiences" such as music lessons, museum visits, owning a computer, etc. are more limited for divorced families due to finances (Levine, 1995, p.45). The educational resources in a new lower-economic neighborhood are many times less than what was available in the previous neighborhood for many divorced families (Levine, 1995, p.61). Children from divorced families are more likely to become "discipline problems" in school (Miller, 1999, p.285; Richmond, 1988, p.33). In the Furstenburg study, $34 \%$ of the children of divorce had discipline problems in school compared to $20 \%$ of children from two-parent homes (Levine, 1995, p.45). Amato's meta-analysis found that children from divorced families scored significantly lower on measures of conduct (Amato, 2001, p.355). Developing social problems in the school 
setting while none are apparent at home is not uncommon (Benedek, 1998, p.10). Getting along with peers may become more difficult (Benedek, 1998, p.60; Hetherington, 1998, p.169; Lansky, 2000, p.43). Overall attitudes regarding school are more negative than in children from two-parent homes (Wallerstein, 1980, p.264). Wallerstein explains that divorce can compromise a child's "receptivity to learning and willingness to experiment with new material" (Wallerstein, 1980, p.264). Children from divorced families are absent from school at higher rates than children from two-parent homes (Lansky, 2000, p.43; Richmond, 1988, p.33) and are twice as likely to have a teen childbirth (Emery, 1999, p.36; Thompson/Amato, 1991, p.14). Involvement in student government and sports is less likely (Gose, 1996, p.35).

With the preponderance of conflicting reports, Amato performed a quantitative meta-analysis in an effort to bring order to the confused and contradictory body of findings (Amato, 1991, p.26). Amato and his associates identified 92 studies that met the following four criteria: involved children from divorced and intact families; contained at least one quantitative measure of well-being; data collected must be capable of calculation of at least one effect size; must involve children as opposed to adult-children of divorce. The results relating to academic achievement showed statistical significance in lower academic achievement in children of divorce when compared to children from continuously married parents (Amato, 1991, p.37). The average effect size of 0.14 standard deviation units was across all child outcomes in the 1991 meta-analysis. Amato recently updated the meta-analysis to include studies performed in the past decade. The findings show that when compared with children from continuously married parents, 
children with divorced parents continue to score significantly lower on measures of academic achievement as well as in the areas of conduct, psychological adjustment, selfconcept, and social relations. The gap decreased in the 80's and has increased again in the 90's (Amato, 2001, p.355). Amato found a shift in the magnitude of effect sizes which are smaller than the earlier meta-analysis. One explanation for the smaller effect sizes is the manner in which the research studies were conducted. Methodologically sophisticated studies of the 90's tend to yield weaker effect sizes due to larger samples (Amato, 2001, p.356). His 2001 meta-analysis concludes that divorce continues to have a negative effect on the academic achievement of children (Amato, 2001, p.355).

\section{Long Term Effects}

Differing opinions exist on the idea of whether or not long-term effects from divorce exist for children. Differing definitions of "long term" also exist, but a commonly accepted definition of "long term" is more than two years while "short term" refers to less than two years (Teyber, 2001, p.10). There is general agreement that in the long run, divorce can definitely have a negative effect on children. Not all authors and researchers agree that divorce was the worst action for the children. Remaining in the environment of a failing marriage also has negative effects. Which is more damaging to a child? "Without access to time machines and parallel universes, this will never be totally resolved" (Wolf, 1998, p.53). Little agreement exists about the extent, severity, and duration of problems because there is great diversity in children's responses to marital transitions (Hetherington, 1998, p.169). Pedro-Carroll, Founder of the Children of Divorce Intervention Program (CODIP), states, "Substantial variation in long-term 
reactions to divorce exist" (Pedro-Carroll, 1997, p.216). Authors repeatedly refer to divorce as an ongoing "process" rather than a singular event with effects occurring throughout the process (Emery, 1999, p.3; Hetherington, 2002, p.3; Sun, 2002, p.486; Wallerstein, 1990, p.297). With this in mind, consider the following opinions.

Resilience of children is a common view. Emery claims that the while divorce is an "exceedingly difficult transition" for children and their parents, the "weight of clinical and research evidence suggests that most children are resilient in the long run" (Emery, 1999, p.20). He continues, "Resilience is the normative psychological outcome of divorce for children" (Emery, 1999, p.37). Belli agrees that children of divorce do not “inevitably" suffer lifetime damage (Belli, 1988, p.201). He states, "No long-term study of thousands of children of divorce from all classes and races in all sections of this country has ever been made" that supports a lasting damage (Belli, 1988, p. 202.) Emery agrees that a major sampling issue in divorce research is whether the sample is representative of a larger population to which findings can be generalized (Emery, 1999, p.21). Teyber states, “The widespread myth that children's lives are forever blighted by divorce is false" (Teyber, 2001, p.3). He explains that there is much parents can do to help their children through the crisis. He suggests that parents eliminate ongoing hostility, eliminate ineffective discipline, prevent loss of contact with a parent, refrain from pressuring a child to side with one parent against the other, and refrain from drawing the child into an adult role of meeting a parent's needs (Teyber, 2001, p.16). The general pattern he has identified is that five to ten years following a divorce, $25 \%$ of the children are doing very well, $50 \%$ have mixed success and problems, and $25 \%$ 
struggle with significant, enduring problems (Teyber, 2001, p.16). Martinez agrees that negative outcomes from divorce can be mediated by positive parenting practices (Martinez, 2002, p.107). Benedek asserts that the effects of divorce will end for a girl in about six months to one year and for a boy in about two years (Benedek, 1998, p.83). Stewart claims children rebound to average levels of mental health by eighteen months (Coontz, 1997, p.22). Belli places the responsibility of long-term effects upon the parents. He states, "You and your spouse are the best determiners of whether or not any long-term damaging effects to your children will result from your divorce" (Belli, 1988, p.202). Berry claims that if the process of divorce is clean and straightforward, longlasting effects will not occur (Berry, 1998, p.202). Neuman states, "The truth is, children can and do live happily after divorce" (Neuman, 1998, p.11). He explains that from divorce "invaluable, lasting lessons for your children about courage, independence, and self-esteem can be crafted" (Neuman, 1998, p.14). In her book directed to preteens, Bode summarizes, "Living through divorce does not automatically cause wounds that never heal. It does not have to be the end of your world. Like a giant puzzle, the pieces of your life can be arranged and rearranged into a vibrant picture. You can learn from your experiences, grow emotionally, and have a happy future (Bode, 2001, p.90). In his meta-analysis of 92 divorce studies, Amato concludes that "most children are psychologically resilient" in coping with parental divorce (Thompson/Amato, 1999, p.13). The most notable differences in resiliency occur at the extreme and not at the center of the distributions (Thompson/Amato, 1999, p.13). The tendency is to overestimate the negative effects due to divorce. Correlation does not equal causation, and problems found after divorce may have been present before the divorce. In cases 
such as these, the effects are not "consequences" of divorce (Thompson/Amato, 1999, p.15). Amato cautions that resilience is not the same as invulnerability. Resilience implies that "kids bounce back" (Thompson/Amato, 1999, p.16). Amato recommends avoidance of the need for children to be resilient (Thompson/Amato, 1999, p.16). "Some children are irreparably wounded by divorce. While the wounds of most heal, even healed wounds usually leave a scar" (Thompson/Amato, 1999, p.18).

In contrast to the previous ideas, Fassel claims "the few longitudinal studies that exist claim that effects are long-lasting and not temporary as previously thought" (Fassel, 1991, p.5). She concludes that divorce is long-lasting in its effects (Fassel, 1991, p.5). Rentmeester agrees that divorce is a "long-term, lifelong process" for children (Rentmeester, 1997, p.163). Jonsson concludes, "Previous studies fairly consistently reveal educational disadvantages for children of divorce as measured by standardized tests, grade point average, exams, diplomas, or years of completed education" (Jonsson, 1997, p.277). He also points out that the long term disadvantages are not as great if researchers control for various background factors. Sun's study assessed children at four sequential time periods extending from three years prior to the divorce to three years after the divorce. He concludes that the "marital disruption process" affects the children continuously (Sun, 2002, p.486).

Several longitudinal studies have been conducted. Above all the previous studies, one researcher comes to the forefront. Judith Wallerstein performed a twenty- five year study with a group of children of divorce. Most other sources quoted her works. Some 
supported them; others refuted them; but few could ignore them. Wallerstein summarizes, "Contrary to what we have long thought, the major impact of divorce does not occur during childhood or adolescence. Rather it rises in adulthood as serious romantic relationships move center stage. When it comes time to choose a life mate and build a new family, the effects of divorce crescendo" (Wallerstein, 2000, p.xxix).

Wallerstein's study of 131 children and adolescents from sixty families who had recently separated and filed for divorce in Marin County, California, began in 1971. Because of the commonly held assumption that divorce was a short-lived crisis, the study was originally designed to last one year (Wallerstein, 1990, p.xv). Because most families were still in crisis one year to eighteen months after the study was initiated, the study was extended. To begin her research, Wallerstein examined the children and parents intensively for six weeks at the time of the initial physical separation. She contacted and reexamined them at eighteen months, five years, ten years, and again at twenty-five years (Wallerstein, 2000, appendix). At eighteen months after separation, most children had passed through the most acute stage of crisis (Wallerstein, 1980, p.163). At the five year mark, 34\% were doing exceptionally well; $29 \%$ were adjusting adequately; $37 \%$ were in poor psychological health defined as moderately to severely depressed; $23 \%$ displayed anger linked to school failure (McKay, 1999, p.191). The anger was manifested by delinquency, sexual acting-out, and anger at the father (McKay, 1999, p.191).

At the ten year mark, 116 of the original 131 were revisited. They were eager to discuss their lives and the effects they still felt. They vividly remembered the "day of 
separation." They resolved not to have children themselves until they were sure of marital happiness. Their anger was tempered with sympathy. Those who were preschoolers at the time of their parents' divorce were better adjusted than the others. The majority received no child support throughout the process. While most parents had remarried within two years, nine out of ten second marriages had failed by this ten year mark. One in eight saw parents find happiness in remarriage. (McKay, 1999, p.193). Wallerstein reached several conclusions at the ten year mark. One conclusion is that it is not possible to predict the long term effects of divorce on children from how they react at the outset (Wallerstein, 1990, p.15). Another conclusion is that the effects of divorce are often long-lasting (Wallerstein, 1990, p.297). Finally, Wallerstein determined that "divorce is not a more 'normal' experience simply because so many people have been touched by it; Our findings reveal that all children suffer from divorce no matter how many of their friends have gone through it" (Wallerstein, 1990, p.303).

At the twenty-five year mark, Wallerstein added a comparison group of two same-age, same-sex adult children from intact families from the same neighborhood for each adult child of divorce. At the twenty-five year mark, the adult children of divorce reflected on their lives and shared their insights. They said that parental anger at the time of divorce was not what mattered the most. The many years of living in a post-divorce or remarried family had the biggest impact. Some of their insights regarding concerns are the following: feelings of sadness, loneliness, and anger during childhood; traveling alone; having no choice in how you spend your time; wondering if you will have financial help for college; worrying about your parents for years; reaching adulthood with 
acute anxiety; asking if you can protect your own child from having these same experiences growing up (Wallerstein, 2000, introduction). Not one of the adult children of divorce wanted their own children to repeat their childhood experiences. The whole trajectory of their lives was altered by the divorce experience. Many of these adult children are stronger for their struggles and think of themselves as survivors who have learned to rely on their own judgment and to take responsibility for themselves. Most do not take relationships lightly and maintain a reverence for a good family life (Wallerstein, 2000, introduction).

Criticisms are directed toward Wallerstein's study. The most common criticism is that Wallerstein initially failed to include a control group from intact families. (Coontz, 1997, p.21; Emery, 1999, p.21; Furstenberg, 1991, p.68; Lansky, 2000, p.3; Levine, 1995, p.58; Pedro-Carroll, 1997, p.213). At the twenty-five year mark, Wallerstein added a control group from intact families from the same neighborhoods as the study group. Other criticisms include small sample size, using mainly White, middle-class families, and using a self- selected group (Lansky, 2000, p.3; Levine, 1995, p.58). Coontz asserts that Wallerstein oversimplifies the cause of the effects by attributing everything to the divorce (Coontz, 1997, p.21). Coontz also observes that Wallerstein's estimates of risk are more than two times as high as other reputable researchers (Coontz, 1997, p.21). In discussing Wallerstein's study at the 10-year mark, Furstenberg summarizes, "It is highly likely that the study exaggerates the prevalence of long-term problems; all problems that emerge after the break-up are blamed on the divorce" (Furstenberg, 1991, p.68). 
A contemporary of Wallerstein, Mavis Hetherington, conducted the Virginia Longitudinal Study during the same time as Wallerstein's study. Both researchers are from Berkeley University, are now in their seventies, have been in a single marriage for over 40 years, have conducted a 25-30 year longitudinal study on children of divorce, and have published a major book on effects of divorce on children in the past 2 years. Similarities end there. Major differences exist between the two studies. Wallerstein's method was intimate interviews with approximately 131 children from 60 families over a period of 25 years. Wallerstein concludes that divorce can adversely affect children into adulthood. Hetherington's method gathered data via questionnaires from 2,500 children from 1,400 families over a period of 30 years. Hetherington concludes that $80 \%$ of the children recover from divorce by the time they reach adulthood. The contrasting studies of Wallerstein and Hetherington are described respectively as "deep but narrow," and "wide but shallow" (McLaughlin, 2002, p.40). Wallerstein presents a more negative view, and Hetherington focuses on positive aspects. (McLaughlin, 2002, p.40).

Hetherington describes the Virginia Longitudinal Study as "the most comprehensive examination of divorce ever conducted" (Hetherington, 2002, p.3). The study included over 2,500 children from 1,400 families who were followed for three decades. The Virginia Longitudinal Study used questionnaires, standardized test measures, observations of family problem-solving sessions, and interviews (Hetherington, 2002, p.285). A comparison group from non-divorced families was added after the first decade of research (Hetherington, 2002, p.5). Hetherington states that while no doubt exists that divorce can devastate lives, negative effects have been 
exaggerated while positive effects have been ignored in much popular and academic writings (Hetherington, 2002, p.5). "Negative long-term effects have been exaggerated to the point where we have now created a self-fulfilling prophecy" (Hetherington, 2002, p.7). In the Virginia Longitudinal Study, most children were resilient two years after the divorce (Hetherington, 2002, p.122). Six years after the divorce, $75 \%$ were functioning "well within the normal range" while $25 \%$ were struggling with emotional, social, academic, or behavioral problems compared with $10 \%$ of the control group experiencing problems (Hetherington, 2002, p.125). By twenty years later, $80 \%$ were able to adapt to their new life and become reasonably well adjusted (Hetherington, 2002, p.228). 20\% of the children from divorced families were "troubled" in comparison to $10 \%$ of children from non-divorced homes (Hetherington, 2002, p.228). Most children from her study looked back on the divorce as a painful experience but were successfully going on with their lives (Hetherington, 2002, p.7). A minority "emerged enhanced" because of the divorce experience (Hetherington, 2002, p.7). The argument that economic stress causes many of the emotional, psychological, and social problems in children of divorce was not confirmed by the Virginia Longitudinal Study (Hetherington, 2002, p.49). Initial responses to divorce were not an indicator of long-term effects on the children. Some appeared to be adjusting well initially, but delayed problems became apparent in adolescence or young adulthood (Hetherington, 2002, p.111). How well the children coped was dependent upon stresses and personal and social resources available to them (Hetherington, 2002, p.112). Hetherington gives two "bottom- line messages" regarding the long-term effects of divorce on children. The first states that "competent, authoritative mothers can provide the support, sensitivity, and engagement their children 
need for normal development." The second is that "flexibility and diversity" exist in divorce. She explains that divorce is not a form of "developmental predestination" and that the "door to positive change always remains open" (Hetherington, 2002, p.229). For most children, the legacy of divorce is largely overcome 20 years after the divorce (Hetherington, 2002, p.253). The Virginia Longitudinal Study concludes that overall, resiliency, a strong "self-righting" tendency, is the norm in the long-term development of children of divorce (Hetherington, 2002, p.279).

Constance Ahrons, author of , conducted the Binuclear Family Study for the National Institute of Mental Health. The study included 98 families in the Midwestern United States randomly selected from one Wisconsin county via public records. Differences exist between her study and those of Wallerstein and Hetherington. Random selection was the initial difference. She studied "normal" divorced families rather than those requesting help via volunteering for participation in a project. Ahrons included both ex-spouses throughout the study. She explains that interviewing both exspouses presents two pictures of the same divorce which yields two entirely different divorces (Ahrons, 1994, p.16). Over the course of six years, Ahrons also interviewed 91 new partners of divorced spouses. Her findings were similar to Wallerstein's. About $50 \%$ had "bad" divorces that caused harm to both children and adults. The other half had "good" divorces that preserved family ties and provided the child with two parents and healthy families (Ahrons, 1994, p.5). Ahrons focuses on the positive models of divorce and explains, "Good models provide direction" (Ahrons, 1994, p.16). If you ask questions founded in negative assumptions, you will receive negative responses. Ahrons 
always asks the positive counterpart first (Ahrons, 1994, p.16). Ahrons identifies two basic factors differentiating children who are and are not damaged. The first factor is continuing the benefit by maintaining family relationships that were important prior to the divorce. The second factor is a generally supportive and cooperative relationship between the parents whether married or divorced (Ahrons, 1994, p.126).

\section{Adult Children of Divorce}

Researchers have studied adult children of divorce. Engel concludes, "Adult children of divorce have emotional reactions that are just as strong as those of younger children" (Engel, 1992, p.25). Fassel states, "Issues you don't resolve as a child, you carry into adulthood" (Fassel, 1991, p.121). The following lists common struggles and characteristics of adult children of divorce: financial worries; uncertainty about the

future in general; uncertainty about future education; fear of being manipulated; feelings of being torn in half emotionally; feeling "familyless"; apprehension about repeating parents' pattern of unsuccessful marriage; overdeveloped sense of responsibility; fear of conflict; use of conflict in relationships; attempt to control; fear of intimacy; wary of commitments; prone to addictions (Fassel 1991, p.6; Engel, 1992, p.25). Individuals other than children of divorce face these issues. The difference is that for adult children of divorce, the divorce is the center of the octopus, and all other factors are tentacles extending from it (Fassel, 1991, p.46). 


\section{Ways Schools Can Support}

"Children of divorce get very little support from adults as their world falls apart. Apparently, during this time, adult friends, relatives, and teachers are hesitant to interfere" (Engel, 1992, p.24). Authors agree that there is much schools and teachers can do to support children as they experience the crisis of their parents' separation and divorce. Sammons states that teachers can have considerable influence on the effect the divorce has on children (Sammons, 2000, p.65). Often children are trapped in the middle of parental conflicts. Schools have the potential to help take children "out of the middle" (Lipnickey, 2001, p.47; Weyburne, 1999, p.57). "Because school is a structured and predictable place, it has the potential to impart a sense of security that may be lacking at home" (Benedek, 1998, p.210). In reference to the children in her study, Wallerstein states that outside of the school, "few institutions touched these children's lives" (Wallerstein, 1980, p.43). She refers to schools as a "continuing presence at a time of great discontinuity" (Wallerstein, 1980, p.44). Wallerstein asserts that teachers should be informed of major changes in a child's life in order to maximize efforts to create a supportive setting (Wallerstein, 1980, p.266). "More than that, we believe that education of teachers should be expanded to include a more comprehensive, complex view of the psychological development of children including the effects of temporary and prolonged stress" (Wallerstein, 1980, p.266). Neuman agrees that school may be the only part of a child's life that does not change with divorce and refers to school as a "haven" (Neuman, 1998, p.51). In her study, Hetherington concludes that the "right kind" of school can measurably increase a child's chances of "successfully navigating life after divorce" (Hetherington, 2002, p.12). Hetherington describes the "right kind" of school as one that 
is more than academically strong. The teachers make the child feel "cared for" and are open and willing to listen. The discipline policy is loving but firm. The institution is the equivalent of an authoritative parent who provides structure, support, and emotional regulation (Hetherington, 2002, p.145). Many children have successfully coped with divorce crisis and have been helped by "unheralded support of teachers and schools" (Sammons, 2000, p.64). Hetherington identified mentoring as an effective support for children. She explains that a "close, sustained, supportive relationship with a competent adult such as a teacher or coach" could be part of the solution to an adverse family situation (Hetherington, 2002, p.144). In her Virginia Longitudinal Study, she found that "being an effective mentor is no short-term thing" (Hetherington, 2002, p.144). Contact with the involved teacher had little effect if the relationship did not last for at least two years (Hetherington, 2002, p.144). Wallerstein agrees that a "close relationship to a friendly teacher" can improve a child's coping capabilities (Wallerstein, 1980, p.277). Pedro-Carroll echoes the idea that a positive relationship with a teacher or other key adult outside the home can aid a child's adjustment (Pedro-Carroll, 1997, p.217). By understanding the impact of divorce, teachers and schools can effectively assist children of divorce through their difficulties (Miller, 1999, p.285). One of the conclusions from Amato's meta-analysis is that supportive programs in school settings have been shown to improve children's functioning following marital disruption (Amato, 2001, p.356). Richardson agrees that school based interventions can help "counter adverse effects of divorce" (Richardson, 1999, p.21). Sun asserts, "Counseling and help should be provided to children both before and after parental divorce in order to minimize the negative effects" (Sun, 2002, p.486). Teyber's summary of the 3-fold way teachers can help 
children experiencing divorce includes anticipating concerns, understanding what the problems mean, and responding effectively (Teyber, 2001, p.4). Authors provide specific suggestions for accomplishing each facet of support.

\section{Support Strategies from Miller}

According to Miller, effective teaching begins with the teacher's understanding of the impact of divorce on the child. A supportive environment, safe channels for children to communicate feelings and problems, instruction on building coping and selfregulations skills, and resources to help parents must be developed (Miller, 1999, p.285).

Educators possess the potential to provide emotional security and support to the child in the areas of recreational, advice-giving, resource, emotional, and positive feedback. Specifically, the teacher can assure the child that their relationship is secure and intact. This reassurance affirms the safety, security, and self-worth of the child. Compassion can be expressed by using tolerant, calming and kind words that communicate acceptance and understanding of the child. Security is fostered by preparing the child in advance for any changes in the routine (Miller, 1999, p.285).

Because the child has had no control over many divorce-related issues in his life, opportunities to exercise personal control can be provided at school. A lack of personal control may threaten a child's "sense of mastery" (Miller, 1999, p.285). Teachers can look for ways the child can influence meaningful classroom procedures, activities, and events. Examples include choice in seating arrangements, groups, activities, and 
homework. Assigning leadership roles to children will increase their sense of personal control (Miller, 1999, p.285).

Miller recommends that educators be tolerant of variability in academic performance. Children experiencing their parents' divorce may be emotionally preoccupied and unable to concentrate on schoolwork. Miller cautions teachers against interpreting inconsistency as a lack of interest, "lazy," or intentional. Calmly discussing problems and possible solutions with students can help refocus their attention and efforts (Miller, 1999, p.286). Expressing faith in the child's character and capacity for growth is paramount. Misbehavior is a natural reaction to divorce. By being less critical and more patient, teachers can assist children in learning new, acceptable behaviors (Miller, 1999, p.286).

Creating safe channels promotes communication. Together with input from the children, teachers can establish a procedure that encourages children to communicate concerns whenever necessary. Applying communication skills to divorce concerns is desired. "Active-reflective listening" in which the teacher listens and restates what the child is saying is effective. Using open-ended questions rather than yes/no questions is recommended. "I" statements are preferred to "You" statements. Clarification of the child's concerns should be expressed. An example of a clarification statement is the following: "Let me make sure I'm understanding..." (Miller, 1999, p.286). 
Coping skills must be taught to the children. The first step is for the child to regain composure. Teachers can help children devise strategies to regain control of their emotions or behaviors. Examples of coping strategies include talking to the teacher, talking to a peer, a personal touch by the teacher, or nonverbal methods of drawing a picture or writing in a journal. Some children may need to respond physically by running in the gym or being sent on an errand. Short breaks can be utilized as a coping skill (Miller, 1999, p.287).

Final words of advice from Miller address expectations and early intervention. "Be firm, yet fair about expectations" (Miller, 1999, p.288). The author explains that teachers must communicate their expectations and then give firm, immediate response to violations. Regarding intervention, Miller states, "Be proactive, not reactive" (Miller, 1999, p.288). As soon as the teacher becomes aware of a child experiencing family disruption, consulting with the school counselor and gaining support for the child is recommended (Miller, 1999, p.288).

While teachers are very capable of supporting children in family disruption, limitations exist. Miller offers the following cautions. Focus on divorce-related problems only as they affect classroom behavior and academic performance. Refer the child to a counselor if chronic problems or stress are present. Discuss the divorce with the parents only in terms of how it affects the child's classroom behavior and academics. Avoid being drawn into taking sides. Be compassionate and a source of support to the child without assuming a parental role. Finally, facilitate access to relevant resources 
without suggesting you will be personally involved in resolving the problem (Miller, 1999, p.288).

Resource ideas for assisting teachers include creating a teacher group to brainstorm strategies, designing or attending a workshop, creating a list of reading resources, asking the librarian for age-appropriate literature, and searching the web. Miller's suggestion for parental resource is to prepare a one-two page handout on how parents can help their children with divorce stress. Requesting that parents inform the teacher about specific issues, how the child is coping, and when new stressful events occur is encouraged (Miller, 1999, p.288).

\section{Support Strategies from Lipnickey}

Communication with schools is often complicated for children of divorce. Many times, only one parent is aware of pertinent school information regarding their child. By establishing a set of policies and procedures to be implemented at the beginning of each year, schools and school boards have the opportunity to help remove children from the middle of parental conflict (Lipnicky, 2001, p.47). The first step in accomplishing the goal of taking children "out of the middle" is to create a database for all students. The information it contains includes the following:

1. Child's name, address, phone number

2. Residential and nonresidential parents' full name, spouse, address, home and work phone numbers, e-mail address, and time child is ordered to spend with each parent

3. Name of parent who is to be contacted in case of emergency

4. Any court-ordered limitations on contact with the child by either parent

5. An inventory of documents on file that are school related to the child (Lipnickey, 2001, p.47) 
The second step is for the school to write letters to both parents of students whose parents do not live together enumerating responsibilities and expectations. When both parents are informed about responsibilities by an independent third party rather than by a former spouse, the information carries greater weight (Lipnickey, 2001, p.47). The letter should clearly explain the following:

1. Student's responsibilities

2. Parents' responsibilities

3. Teacher's expectations

4. School's expectations (Lipnickey, 2001, p.47)

Examples of topics of responsibilities and expectations include academic performance, homework assignments, permission slips, attendance, punctuality, dress code, fees, and others (Lipnickey, 2001, p.47).

Students should be instructed to deliver all school documents to the "residential parent for school purposes," and the school should mail copies to the non-residential parent unless restrained by court order (Lipnickey, 2001, p.47). Both parents should be encouraged to attend the same parent-teacher conference so that they receive identical and simultaneous information. By handling communication, schools can remove some of the stress from the children (Lipnickey, 2001, p. 47). Lipnickey recommends developing support groups comprised of children of divorce as an additional avenue of support. In a telephone interview with the researcher, Lipnickey revealed that most of her information originated from years of personal experience in her law practice. 


\section{Support Strategies from Sammons and Lewis}

Sammons and Lewis maintain that teachers can have considerable influence on the effect divorce has on their students (Sammons, 2000, p.65). Because the teachers and students spend much time together, teachers can observe behaviors and give clues regarding struggles to parents and professional counselors. Teachers help shape strategies that enable children to thrive (Sammons, 2000, p.64).

Suggestions are directed toward teachers. Maintaining consistency and discipline can increase the security of the child. By allocating specific, achievable tasks and responsibilities, teachers can make the children feel competent. Before leaping to conclusions about a child's anxieties, actively encourage the child to express how he views a situation and listen carefully to the child's point of view. Be an advocate for the child by encouraging parents to work together for the child's best interest. Finally, keep both parents involved. Newsletters and notices should be sent to both parents. In contrast to Lipnickey's advice, Sammons asserts that individual conferences with each parent should occur in which information is obtained and feedback is given (Sammons, 2000, p.65).

\section{Support Strategies from Diamond}

Diamond provides practical suggestions for teachers to offer support to children from divorced families. She focuses on "sensitizing" teachers to common situations that children may face (Diamond, 1985, p.31). The following is her list:

1. Assume some children are not living with both natural parents; then identify those students (Diamond, 1985, p.31). 
2. Get the name s right (Diamond, 1985, p.32).

3. Make it easy when written communications or gifts are to be sent home. Offer options; everyone makes two, etc. (Diamond, 1985, p.33).

4. Avoid embarrassing questions (Diamond, 1985, p.34).

5. Respect confidentiality (Diamond, 1985, p.34).

6. Recognize that certain class projects may cause embarrassment. Take advantage of opportunities to legitimize differences (Diamond, 1985, p.35).

7. At Open House, expect from 1-4 parents (Diamond, 1985, p.36).

8. Maintain an open mind regarding the worth of single-parent families (Diamond, 1985, p.36).

\section{Support Strategies from Brodkin}

Dr. Brodkin provides five principles for promoting healing in children of divorce.

They include the following:

1. Keep reaching out to the parents.

2. Suggest professional guidance or counseling.

3. Provide support for the child.

4. Develop individualized learning that includes activities regarding divorce.

5. Integrate support into learning (Brodkin, 1995, p.30).

\section{Support Strategies from Barr}

Barr took a slightly different approach by asking individuals who had experienced the divorce of their parents when they were children how teachers could help children through divorce. The following suggestions resulted:

1. Understand why I'm upset (girl, age 8).

2. Don't yell at me for daydreaming. Please give a little extra bit of help and care (girl, age 16).

3. Teach me how to handle problems (boy, age 10).

4. Give advice on how to keep grades up (boy, age 9).

5. Let students know you are available to talk about any problem (girl, age 17). 
6. Don't assume kids live with both parents (girl, age 18).

7. Be more aware of "What does daddy do?" type questions (boy, age 29).

8. Listen (girl, age 17).

(Barr, 1982, p.133).

\section{School-Based Intervention Programs}

Programs in the school setting have been shown to improve the functioning of children following marital disruption (Amato, 2001, p.356). Amato expresses the continuing importance of developing and evaluating therapeutic and education programs for children of divorce (Amato, 2001, p.366). Manning recommends organizing support groups where children can talk about and work through their experiences. He explains, "No one knows more about the emotional turmoil of divorce than the children of divorce themselves" (Manning, 1991, p.13). Through interviewing children of divorce, Bode concludes that what helps them the most is to talk about changes and listen to advice from others in similar situations (Bode, 2001, p.8). Richardson identifies three characteristics of any effective school-related intervention. First, the intervention should develop a strong support system for the child. This is accomplished by involving parents through questionnaires, meetings, and parent-child interactions. Teachers are involved in the support system by rating the child's behavior. In addition, the intervention should foster peer support (Richardson, 1999, p.25). Secondly, the intervention program should focus on building skills. Finally, flexibility of the program to allow modifications to accommodate children of different gender, ethnicity, and socioeconomics is needed (Richardson, 1999, p.25). Richardson states, "It is clear that continued utilization of 
effective school-based interventions for children of divorce could only help these children deal with an often confusing and painful situation" (Richardson, 1999, p.25).

Goldman and King developed a schoolbased program in 1985. This program incorporates activity groups, teacher training and parent involvement and is designed for elementary and young adolescents. The flexibility of the program allows it to extend from six to twelve weeks. Ideally, meeting one hour for ten weeks is the preference of this program. Teachers are involved by completing written evaluations of each participant both at the beginning and at the conclusion of the program's duration. The study showed that children who were just beginning to experience divorce showed more improvement than children whose parents had been divorced for two years or longer (Richardson, 1999, p.23).

McGonagle founded "Banana Splits" in 1989. This school based peer support program for children of divorce generally meets during the scheduled lunch times of students. Students discuss divorce-related issues with other students and a school counselor approximately one time every-other week (Kimball, 1994, p.120).

Stolberg and Mahler developed a school-based program in 1989 and updated it in 1994. This program lasts fourteen weeks. The three components of skill building, skills transfer, and support are the program's objectives. The skill building focuses on identifying feelings while the skill transfer addresses parents through workshops. The skill building segment yielded significant adjustment gains (Richardson, 1999, p.24). 
Sanders and Riester developed a school-based program in 1996. This program meets for 30-minute weekly sessions over ten weeks. Two goals comprise the program: to enhance children's understanding of divo rce and to teach ways for children to cope with divorce. The results yielded improved peer relations and feelings of social acceptance (Richardson, 1999, p.24).

Pedro-Carroll and Alpert-Gillis developed the Children of Divorce Intervention Program (CODIP) in 1982. The program was expanded in 1992. CODIP contains seven goals based upon Wallerstein's principles of what can help children through divorce (Richardson, 1999, p.25). The results yielded the following: benefit in adjustment, diminished anxiety, fewer negative attributions, and realistic perceptions of situations children can and cannot control (Richardson, 1999, p.24).

\section{Children of Divorce Intervention Program (CODIP)}

In discussing divorce-related research, Pedro-Carroll explains that past research has focused more on risk factors for negative outcomes than on protective factors that favor adaptive outcomes (Pedro-Carroll, 1997, p.216). She concludes that more research is needed to identify pathways to wellness. Factors identified for promoting wellness include authoritative, nurturant, effective parenting, sound parent-child relationships, parental cooperation in child-related matters, minimal interparental conflict, and effective coping strategies (Pedro-Carroll, 1997, p.216). Factors for negative adjustment include high interparental conflict and maladaptive coping styles (Pedro-Carroll, 1997, p.217). 
Pedro-Carroll asserts that preventive interventions are needed to teach children effective coping strategies (Pedro-Carroll, 1997, p.217). CODIP was developed in 1982 with two goals in mind: 1) minimize divorce's negative impact on children; 2) teach children skills and competencies to help them cope in maximally adaptive ways with the major challenges in the aftermath of divorce (Pedro-Carroll, 1997, p.218). Wallerstein's concept of specific psychological tasks confronting children of divorce is reflected in the program's defining features for different ages (Pedro-Carroll, 1997, p.218). The schoot based program seeks to create a supportive environment where children can freely share experiences, establish common bonds, and clarify misconceptions. It also teaches children skills that enhance their capacity to cope with stressful changes that often accompany divorce (Pedro-Carroll, 1997, p.218). Curriculum is available for the following four combinations of grades: Kindergarten and $1^{\text {st }}$ grade, $2^{\text {nd }}$ and $3^{\text {rd }}$ grades, $4^{\text {th }}$ through $6^{\text {th }}$ grades, and $7^{\text {th }}$ through $9^{\text {th }}$ grades. Each age group shares the following seven program objectives:

1. Provide a supportive group environment

2. Help children identify and appropriately express feelings

3. Promote understanding of divorce-related concepts and clarify divorce-related misconceptions

4. Enhance coping skills in problem solving, effective communication, support seeking, and appropriate expressions for anger

5. Enhance child's positive perception of self and family

6. Foster parent-child communication

7. Facilitate a smooth group termination with maintenance of support (Pedro-Carroll, 1997, p.218).

The initial study by Alpert-Gillis and Pedro-Carroll involved 52 families of divorce and 81 intact families. A pre-post design was used. Children, parents, teachers, 
and group leaders were involved in rating adjustment measures. The measurement tools included a seventeen item Children's Divorce Adjustment Scale (CDAS), a twenty item Parent Evaluation Form (PEF), Group Leader Evaluation Form (GLEF), Teacher-Child Rating Scale (T-CRS), and a thirty-six item Child Rating Scale (CRS). The CRS measured the child's perceptions of school problems and competencies based on rule compliance, anxiety/withdrawal, social skills, and self-confidence (Alpert-Gillis, 1989, p.583).

CODIP support groups meet at schools for 10-15 weekly sessions of 45 minutes to an hour. The ideal arrangement is co-led by a male and a female. The success of CODIP depends on the interest and skills of the group leaders (Pedro-Carroll, 1997, p.222). Group leaders must possess sensitivity and have the ability to establish a trusting environment. CODIP leaders are selected more for interest, skill, and sensitivity than for training in any specific discipline. Four or five training sessions of two hours are attended before the program begins. $\mathrm{Bi}$-weekly ninety-minute training-supervision sessions continue during the duration of the support groups.

Letters on school letterhead should be sent to school families to inform parents of the formation of CODIP groups. To qualify for participation in CODIP, a child must be within the target age range. He must have parents who are currently separated or divorced. He must be capable of functioning adequately in a group setting. Written parental consent must be obtained prior to participation. 


\section{Support Strategies Directed toward Parents}

Some authors direct their suggestions for supporting children from divorced homes to the parent. While the intent of the author is to equip parents, teachers may benefit from the information contained in the advice. Applications may be made to school settings. Strategies that do not apply directly to educational settings may be instrumental in increasing the educator's understanding and sensitivity. Value exists in considering articles addressed to parents.

\section{Support Strategies from Benedek}

Benedek addresses specific emotions and problems and directs her suggestions to parents. While not every child experiences every emotion and challenge, "by knowing what to expect, you will be better equipped to help your children deal with the ones they do experience" (Benedek, 1998, p.61).

In addressing fear, Benedek recommends helping the children verbalize their fear by asking them to describe of what they are afraid. To alleviate a child's fear, continual reassurance is needed. Consistent and reliable behavior of adults in the child's life can reduce fear. Above all, being available for the child will provide the support needed to combat the fear (Benedek, 1998, p.62). 
Intense sadness is a common emotion present in children experiencing their parents' divorce. The best way to help children handle their sadness is to give them permission to express it and talk about it on their own terms (Benedek, 1998, p.63).

Anger is often present as children deal with changes due to divorce. Do not deny their anger but rather permit them to express it in acceptable ways. It may be necessary to assist the child in finding avenues that are acceptable. Physical activity is a suggested outlet (Benedek, 1998, p.64).

Many children are overcome with feelings of guilt. They assume responsibility for their parents' divorce. In all cases, repeatedly tell the child that he is not the cause of the divorce and that the divorce is permanent. Children must be continually told that there is nothing they did to cause the divorce and there is nothing the y can do to get the family back together (Benedek, 1998, p.65).

Feelings of loneliness often accompany the divorce experience for children. Providing opportunities for children to grow intellectually can ease the loneliness. Recommended activities include reading, drawing, journaling, shooting baskets, and similar activities. Benedek cautions against using television or video games as a diversion because these are passive and do not encourage imagination. She further cautions that unmonitored television can increase aggressiveness in children (Benedek, 1998, p.67). 
Related to loneliness is a sense of rejection. One eight year old boy experiencing his parents' divorce explains, "I don’t fit in anywhere. I feel like my insides are missing" (Benedek, 1998, p.68). To eliminate feelings of rejection, always give unconditional acceptance (Benedek, 1998, p.68).

In addition to emotions, particular behaviors may surface. Regression may occur in which children revert to behaviors from earlier developmental periods. Examples include thumb-sucking, bedwetting, clinging to parents, and others. Benedek's advice is to simply be patient with children exhibiting regression; it will pass (Benedek, 1998, p.69). Sleep problems may develop. Establishing a bedtime routine can help with this. Benedek cautions both against remaining in the child's room until he falls asleep and against allowing the child to sleep with the parent. The short-term solutions can exacerbate long-term difficulties (Benedek, 1998, p.70). Physical problems such as stomachaches, headaches, cramps, and chest pains, are usually real and should be treated in this manner (Benedek, 1998, p.71). Professional help is recommended if anorexia, bulimia, or excessive masturbation develop (Benedek, 1998, p.72). For school-related problems, Benedek suggests meeting regularly with the teacher (Benedek, 1998, p.71).

Benedek summarizes "What kids need most" with the following list:

1. Be available to spend time and discuss feelings.

2. Acknowledge and empathize with their feelings.

3. Do not criticize the other parent; encourage love for both parents.

4. Keep conflict with ex-spouse to a minimum.

5. Help deal with loneliness by helping them become confident that they can handle almost any situation.

6. Do not punish or ridicule regressive behavior.

7. Limit television and video games. 
8. Respect the child's need for privacy.

9. Keep tabs on your kids; Always know where they are (Benedek,1998, p.84).

\section{Support Strategies from Wolf}

Wolf directs his suggestions to parents. Listening is a major theme. He states, "Despite divorce, there is much that remains within a parent's power that can yet determine whether their children and they with their children can have a nice life" (Wolf, 1998, p.12). One of the keys is knowing how to listen and talk. He explains that success in helping children is not contingent upon knowing answers to everything (Wolf, 1998, p.41). "Very often the best response to much of what kids say is to listen" (Wolf, 1998, p.46). As the children experience grief, soothing answers will not help. Wolf states, "Just listen and be there for them" (Wolf, 1998, p.18).

\section{Support Strategies from Neuman}

Neuman developed the Sandcastles Program, an international organization that provides support groups for ages 5-17. Over 20,000 children and parents have participated in the Sandcastles Program which consists of a one-time $3 \frac{1}{2}$ hour support group (Neuman, 1998, p.9). In discussing divorce, Neuman encourages parents to allow children to learn from mistakes of the parents (Neuman, 1998, p.14). Reiterating to any age child the truth that the divorce is not the child's fault is imperative (Neuman, 1998, p.124). Neuman encourages parents to engage in casual conversation rather than ask direct questions of their children. Examples of times when casual conversation could be 
used include while baking cookies with your child or while riding in the car together (Neuman, 1999, p.153). Making private time with each child a priority and maintaining routines are suggestions. Regarding the ex-spouse, sharing the responsibility for the divorce along with the ex-spouse, banning "bad-mouthing," and keeping children out of the middle of conflict are principles to follow. Neuman recommends that parents let the children know that each parent is capable of caring for himself. He cautions against rushing into romance but to never stop saying "I love you" to the child (Neuman, 1999, p.153). 
Chapter III: Divorce Study in the Christian School

While much research regarding effects of divorce on children and interventions has been conducted in public school settings, research in the Christian school setting is lacking. The purpose of the current study was to examine effects of divorce on children in a Christian school setting and to determine ways Christian schools could support the children.

\section{Permission from Administration and Executive School Board}

To initiate the study, the Christian school administrator was contacted. In a private meeting between the administrator and researcher, the purpose and methods of the study were discussed. The purpose encompassed studying the effects of parental separation and divorce on children and what the Christian school could do to support the children of divorce. A major goal of the study was to offer assistance for children of divorce through teacher-led peer support groups without giving offense to anyone. Participating children would attend 10-15 weekly support sessions with peers led by teachers for 45 minutes after school. Curriculum purchased by the researcher from the Children of Divorce Intervention Program (Appendix I) was used. Confidentiality was maintained. The desired outcome was to support the children from divorced families and to help them thrive in the Christian school.

Between 20 and 40 separated or divorced families with children from Kindergarten to Sixth Grade were desired as willing participants. Potential families with 
separated or divorced parents were identified by examination of school records by the researcher. A confidential letter explaining the study and requesting interest and permission to participate was sent to potential families. Examining students' attendance and academic records was necessary. Participation in open-ended questionnaires or attitude scales for parents and children, personal interviews with parents and children, and personal interviews with teachers and administration was involved. A second group of 20 to 60 families in which parents are not separated or divorced who have children from Kindergarten to Sixth Grade was needed as a comparison group. A letter was sent to all school families with parents who are not divorced. This letter did not explain the purpose of the study as it related to divorced families but rather requested permission to examine the child's attendance and academic records and to administer an attitudinal questionnaire in early September and again in December to the student. A control group was randomly selected from all non-divorced families granting permission to participate.

At this point, the direction of the study was uncertain and dependent upon several factors: administrative permission and guidance; Executive School Board permission and guidance; available population of separated and divorced families within the school; willingness of divorced parents to allow the researcher to involve them and their children; willingness of families that are not separated or divorced to allow the researcher to involve their children; willingness of teachers to assist in leading support groups. The life of the study itself was dependent upon the responses of these factors. The study held within it the potential to metamorphose. The administrator agreed to favorably convey the study to the Executive School Board in the following week's meeting. A copy of the 
research proposal, Chapter One of the thesis, was given to the administrator. The administrator requested that a release form be drafted for teachers who participate in leading the groups (Appendix A). He also requested a brief, written summation of the goals and methods of the study (Appendix B) to present to the Executive School Board along with copies of the two letters (Appendices $\mathrm{C}$ and $\mathrm{E}$ ) and two permission forms (Appendices D and F) for divorced and non-divorced families. The following week upon reviewing the information provided by the Administrator, the Executive School Board granted permission for the study to commence.

\section{Enlisting Group-Leaders from Teachers}

While the number of students participating in the study was completely unknown at this juncture, the possibility of needing multiple support groups was real. The next step the researcher chose to complete was enlisting potential group leaders from the elementary staff. A general e-mail describing the thesis study, the peer support groups, and the need for leaders was sent to all twelve elementary classroom teachers (Appendix H) on the staff. Uncertainty involving number of students, ages of students, and number of groups and leaders needed existed. Time commitment was significant involving 45minute sessions after school for 10-15 weeks and preparation time preceding each session. With the time commitment involved, the researcher desired to gain a Continuing Education Unit for the teachers who would participate. After discussing the possibility with the administrator, the researcher completed the required form for Association of Christian Schools International, and the administrator submitted the information. ACSI agreed to grant one CEU for each teacher who participated. Four teachers responded 
with a willingness to become a group leader. With the researcher, the total potential pool of leaders numbered five. The researcher thanked them for their willingness and promised to keep them informed regarding progress toward developing the groups. Contact via e-mail and direct conversation with individuals continued throughout the next few weeks.

\section{Identifying Potential Participants}

With permission granted from Administration and the Executive School Board, identification of families with separated or divorced parents became the next step. This involved examining every elementary child's school file. Because files are confidential, they could not be removed from the office. An office key was borrowed from the elementary principal, and a Saturday was selected. Determining which students were from separated or divorced families was a challenge. Original enrollment registration contained information on parents in which they identified themselves as married, separated, divorced, widowed, remarried, or single. Re-enrollment forms did not contain information regarding marital status of parents. Both original registration and reenrollment forms did, however, request information regarding with whom the child lives. Choices included both parents, mother only, father only, or other arrangements with explanation. Both forms contained separate lines requesting the addresses of father and mother. To determine the family status as divorced or continuously married, original registration and subsequent re-enrollment forms were examined. It was possible for separated or divorced parents to select "child lives with both parents" on the reenrollment form if the parents had joint-custody. To identify children from separated or 
divorced homes, the most current re-enrollment form was first checked for with whom the child was living. If both parents were selected, the home addresses of each parent were compared. If the addresses were different, the chance existed that the child lives in two separate homes. Previous re-enrollment and original registration were also checked for changes in the child's and parents' names and addresses.

To begin the identification process, the researcher along with two other teachers removed one grade level's folders at a time from the file cabinets. Each student's folder was carefully examined to determine whether or not the child lived with separated or divorced parents or with parents who were continuously married. As a child from a separated or divorced home was identified, the following information was recorded on computer using Excel: Name of child, grade level of child, homeroom teacher of child, mother's name, father's name, with whom the child lives, siblings attending the school.

The 344 files of students in Kindergarten through Sixth Grade were examined. 37 children from 27 families were identified from separated or divorced homes. The remaining 307 children were from 220 families with parents who were continuously married. With the possibility of including only 27 families involving separation or divorce in the study and with the desired minimum of 20 families for statistical purposes, the condition of the study was somewhat precarious. The researcher proceeded with the next step of preparing the mailing. 


\section{Initial Mailing}

Displaying their support for the study, the administration provided school letterhead, school envelopes, return-envelopes, labels, and permission to use the school copier and other necessary office equipment for the project. Labels for all elementary school families were printed by the school office staff. The labels were addressed to the parent and gave the grade levels of the students. A high school student assigned as a regular assistant to the researcher stamped all envelopes with "Confidential." She labeled every return envelope with the researcher's name and included the researcher's name on the upper left corner of the main envelopes above the school's address. Copies of both letters, 40 for divorced families and 250 for non-divorced families, were made on school letterhead by the researcher. 330 copies of permission forms for non-children of divorce were made on plain, white paper. 50 copies of permission forms for children of divorce were made on yellow paper. All letters and forms were sent through the paper folder. Using the information from the Excel spreadsheet prepared earlier by the researcher and assistants, the mailing was assembled by the researcher. Each family received only one letter depending upon their status as separated/divorced or continuously married. Each family received a permission form for each child from Kindergarten through Sixth Grade in their family. The white permission forms were included in the non-divorced family envelopes, and the yellow permission forms were included in the separated/divorced family envelopes. Every family received a return school envelope marked "confidential" addressed to the researcher. The contents were sealed in an envelope marked "confidential" and addressed to the parent. 
The office provided a class list for each section of Kindergarten through Sixth Grade. The researcher separated the mailing into homerooms. If multiple children were in a family, the letter would be sent through the oldest child. A pre-existing procedure of the school greatly facilitated the mailing. Every Friday, every elementary student brings home a school folder containing completed work, tests, communications from the teacher, and communications from the school. Parents are expecting this folder. They sign it and return it the following school day. The confidential letters were delivered to the teachers who placed them in the weekly folders. Return letters would be received when the folders were returned to the teachers on Monday.

\section{Cataloging Results of Responses}

A 3-inch 3-ring binder was used to collect and sort returned permission forms. Potentially, 344 forms could be returned. Dividers separated grade levels. Class lists were placed behind grade levels. "COD" indicating "child of divorce" was written in the left margin before the name of every child from a separated or divorced home. As confidential responses were received, the researcher recorded information beside the child's name on the class list. If permission was granted to participate in the study, the name was highlighted with green. If permission was not granted to participate in the study, the name was highlighted with red. If a form was not complete, the name was marked with blue, and an explanation was written beside the child's name. For example, a parent may have granted permission to participate in the study but did not check the release statement. Such responses were coded as blue. Information obtained from the permission slip included whether the child had attended only Christian schools or a 
combination of Christian schools, public schools, or other. This information was recorded beside the child's name on the list for future reference. The actual permission forms were placed inside the binder in alphabetical order behind the appropriate grade level.

Of the 247 letters sent home in weekly folders on August 29, 2002, to parents of 344 children, 162 responses were returned to the researcher the following week. 153 responses came from children from non-divorced homes, and 9 responses came from separated or divorced homes.

\section{Follow-Up Letter}

A generic follow-up letter (Appendix G) thanking parents for their responses and requesting that others who had not yet had the opportunity to return their forms please do so in this week's folder was prepared. 350 copies were printed on school letterhead. The open letter contained no confidential material and was simply placed inside every child's weekly folder on September 5, 2002.

The following week, 44 more responses came for children from non-divorced homes, and 17 more responses came for children from separated or divorced homes. These responses were catalogued following the procedure described with the set of first responses. 


\section{Summary of Responses}

From the initial mailing, 153 responses were received from non-divorced homes. 124 granted permission for their child to be included in the study, and 26 denied permission. 3 were disqualified due to an error in completing the form. From the initial mailing, 9 responses were received from separated/divorced homes. 3 granted permission for their child to be included in the study and support groups, and 6 denied permission.

From the follow-up letter, 44 additional responses were received from nondivorced homes. 34 agreed to participate in the study, and 10 denied permission. No response was received for 110 children from non-divorced homes. From the follow-up letter, 17 additional responses were received from separated/divorced homes. 10 agreed to participate in the study, and 7 denied permission. No response was received for 11 children from separated/divorced homes. One divorced parent who denied permission wrote an angry note that any type of "study" would take place that involved children from divorced homes. This response was the single opposition voiced to the researcher regarding the study.

With a total of 158 positive responses, $51.5 \%$ of the responses from non-divorced families agreed to participate in the study. With a total of 36 negative responses, $11.7 \%$ of the responses from non-divorced families denied participation in the study. With 3 errors, $0.9 \%$ incorrectly completed the form. With 110 not giving any response, $35.8 \%$ 
chose not to respond to the study. With 197 total responses from the 307 contacts into non-divorced homes, $64.2 \%$ acknowledged receiving the contact and responded to it.

With a total of 13 positive responses, $35.1 \%$ of the responses from separated/divorced families agreed to participate in the study. With a total of 13 negative responses, $35.1 \%$ of the responses from separated/divorced families denied participation in the study. With 11 not responding, $29.7 \%$ chose not to respond to the study while $70.3 \%$ chose to respond either positively or negatively.

\section{Participants}

Eight of the thirteen children from separated/divorced families were able to meet at the Tuesday times which had been designated in the original letters. For four children whose parents agreed to allow their children to participate in the study, the Tuesday times conflicted with current schedules. After making numerous attempts to choose alternate times, Tuesday remained the time that complimented the most schedules. Three weeks into the study, two additional participants joined the study: a male in second grade and a male in fifth grade. The ten participating children from separated/divorced homes included one kindergarten male, two $2^{\text {nd }}$ grade males, one $3^{\text {rd }}$ grade male, two $4^{\text {th }}$ grade females, two $5^{\text {th }}$ grade males, and two $6^{\text {th }}$ grade females. Two support groups were formed: a younger group including the four children in $3^{\text {rd }}$ grade and younger, and an older group including six children from $4^{\text {th }}-6^{\text {th }}$ grades. The researcher became the group leader for the older group and was assisted by a $4^{\text {th }}$ grade teacher. A second grade teacher became the group leader for the younger group and was assisted by another $2^{\text {nd }}$ 
grade teacher. The fifth teacher who had volunteered to lead a group if needed agreed to not participate in the sessions at this time.

Selection of a comparison group from non-divorced families was the next step. Two students of the same gender and grade level were randomly selected from all students of that same gender and grade level for each student from separated/divorced homes who were participants. Each qualifying student from non-divorced homes was assigned a number, and then numbers were drawn from a bag. An additional qualification was that the student had attended only Christian schools for his educational career. Surprising to the researcher, only 8 students of the 158 potential participants were disqualified with the additional requirement of attending only Christian schools. A letter informing parents of the random selection of their child (Appendix O) was sent. Additional control subjects were not selected for the two children who joined the study three weeks after it had begun. However, the control group already included children of the same gender and grade level as the two additional participants.

\section{Measurement Tools}

Because the selected intervention was chosen to replicate the Children of Divorce Intervention Program developed by JoAnne Pedro-Carroll from Rochester, New York, the measurement tools selected for the study were the ones used in her research. The original measurement tools included a seventeen item Children's Divorce Adjustment Scale (CDAS), a twenty-four item Parent Evaluation Form (PEF), Teacher-Child Rating Scale (T-CRS), and a thirty-six item Child Rating Scale (CRS). The CRS measured the 
child's perceptions of school problems and competencies based on rule compliance, anxiety/withdrawal, social skills, and self-confidence (Alpert-Gillis, 1989, p.583). The copyrighted Teacher-Child Rating Scale and the Child Rating Scale can be purchased from CODIP. Permission was granted from Pedro-Carroll to the researcher to use, but not publish, the Parent Evaluation Form and the Children's Divorce Adjustment Scale which has been renamed the Children's Family Adjustment Scale. The address to obtain the measurement tools is included in Appendix I. The design for use of the tools was pre/post intervention. The Child-Rating Scale was used with both the non-divorced control group and the experimental group. The Parent Evaluation Form, Teacher-Child Rating Scale and the Children's Family Adjustment Scale were used only with the experimental group. Cumulative school records for both groups were examined for attendance information, academic averages, and Stanford Achievement Test national percentiles.

\section{Metamorphosis of the Study}

The original intent of the researcher was to complete a quantitative study capable of statistical analysis and making inferences to the general population of students from separated or divorced homes attending Christian schools. With a sample size of 10, statistical analysis became less practical and making inferences became absurd. After discussing the condition of the study with graduate school advisors, the study was shifted to a qualitative approach in which a small number is examined in depth. The comparison

group from non-divorced families was preserved. The children were given the Child Rating Scale in September and again in December. The purpose of keeping the 
comparison group was to measure over-all sense of well-being during a particular time frame. If, for example, this study had taken place during the time when the terrorist attacks of September 11, 2001, occurred, results of tools measuring sense of well-being of children from separated or divorced families could be greatly distorted unless compared with scores from a group of children from non-divorced families who also experienced the horror of the attacks. At the beginning of the study, the Parent-Child Rating Scale was used for the children participating in the intervention. The TeacherChild Rating Scale was used only one time in the study to obtain information for discussion.

\section{Descriptive Statistics}

While a sample of ten children was insufficient for making inferences to a population, descriptive statistics may reveal pertinent characteristics about the sample. By examining confidential cumulative files of the participants and the comparison group, data was collected. Report cards for the first quarter of the current school year had been issued and copies were placed in the files. Attendance records were examined for the number of absences and days tardy for the first quarter consisting of 57 days. Attendance records for the entire previous school year were also examined. Current academic averages of each student were determined by using SPSS to find each child's mean from all the academic subjects listed on the current report card for the first quarter. When available, national percentiles from the previous school year's Stanford Achievement Test 9 for the complete battery were collected from the cumulative files. Because this was their first year in school and report cards were not numerical in nature, data was 
unavailable for kindergarten age children including one male in the participating group and two males in the comparison group. SPSS was used to determine the mean, standard deviation, standard error of the mean, and range for each of the following tables. The experimental group was from separated or divorced families, and the control group was from continuously married families.

Table 1: Days Absent: First Quarter of 2002-2003 School Year

\begin{tabular}{|l|l|l|l|l|l|}
\hline Group & Mean & SD & $\mathrm{N}$ & S.E. Mean & Range \\
\hline experimental & 1.00 & 1.58 & 9 & .527 & 5.00 \\
\hline control & .857 & 1.17 & 14 & .312 & 4.00 \\
\hline
\end{tabular}

Table 2: Days Tardy: First Quarter of 2002-2003 School Year

\begin{tabular}{|l|l|l|l|l|l|}
\hline Group & Mean & SD & $\mathrm{N}$ & S.E. Mean & Range \\
\hline experimental & 1.67 & 2.87 & 9 & .957 & 8.00 \\
\hline control & 0.64 & 1.60 & 14 & .427 & 6.00 \\
\hline
\end{tabular}

Table 3: Days Absent: Complete 2001-2002 School Year

\begin{tabular}{|l|l|l|l|l|l|}
\hline Group & Mean & SD & N & S.E. Mean & Range \\
\hline experimental & 8.33 & 7.79 & 9 & 2.60 & 19.00 \\
\hline control & 5.62 & 3.10 & $13^{*}$ & .859 & 11.00 \\
\hline
\end{tabular}

*contains 13 because one student's records were not available 
Table 4: Days Tardy: Complete 2001-2002 School Year

\begin{tabular}{|l|l|l|l|l|l|}
\hline Group & Mean & SD & N & S.E. Mean & Range \\
\hline experimental & 5.67 & 7.23 & 9 & 2.41 & 18.00 \\
\hline control & 1.85 & 2.67 & $13^{*}$ & .749 & 9.00 \\
\hline
\end{tabular}

*contains 13 because one student's records were not available

Table 5: Academic Average: First Quarter of 2002-2003 School Year

\begin{tabular}{|l|l|l|l|l|l|}
\hline Group & Mean & SD & N & S.E. Mean & Range \\
\hline experimental & 93.89 & 2.85 & 9 & .949 & 7.00 \\
\hline control & 95.93 & 1.44 & 14 & .385 & 6.00 \\
\hline
\end{tabular}

Table 6: National Percentile: Stanford Achievement Test 9 Complete Battery

Spring, 2002

\begin{tabular}{|l|l|l|l|l|l|}
\hline Group & Mean & SD & N & S.E. Mean & Range \\
\hline experimental & 71.56 & 14.16 & 9 & 4.72 & 42.00 \\
\hline control & 74.64 & 19.72 & 14 & 5.27 & 70.00 \\
\hline
\end{tabular}

Table 1 displays the days absent from school in the first quarter of the current school year. The children from separated or divorced homes were absent 0.143 days more than were children from continuously married two-parent homes. Table 3 shows that the entire previous school year, students from separated or divorced homes were absent an average of 2.71 days more than students from continuously married two-parent 
homes. Table 2 displays that students from separated or divorced homes were tardy an average of 1.03 days more than students from continuously married two-parent homes in the current school year. Table 4 shows that the entire previous school year, students from separated or divorced homes were tardy an average of 3.82 days more than students from continuously married two-parent homes. The academic average for the first quarter of the current school year displayed in Table 5 shows that the academic average of students from separated or divorced homes is 2.04 grade points lower than the academic average of students from continuously married two-parent homes. The national percentiles from the Stanford Achievement Test 9 Complete Battery given in spring, 2002, are given in Table 6. The national percentile for students from separated or divorced homes was an average of 3.08 percentiles lower than those of students from continuously married twoparent homes. The results suggested that the students from separated or divorced homes involved in this study had more days absent, more days tardy, lower academic averages, and lower national percentile rankings on the Stanford Achievement Test 9 than did the children involved in this study from continuously married two-parent homes. A closer look at the raw data reveals that the range of absences from the current school year for children of continuously married two-parent ho mes is $0-4$, and the range of tardies was from 0-6. All children in the control group were tardy either 0 or 1 days with the exception of one child who was tardy on six occasions. Eleven children from this group were absent 0-1 days, two were absent two days, and one was absent 4 days. From the group of children from separated or divorced homes in the current school year, eight were tardy $0-1$ days, and one was tardy 8 days with a spread from $0-8$. Eight were absent $0-1$ days, and one was absent 5 days with a range of $0-5$. The raw data from the entire 
previous school years revealed a range of 2-12.5 days absent for children from continuously married two-parent homes and a range of 0-9 days tardy. Eleven children were tardy 0-2 days, and two others were tardy 6 and 9 days. The raw data from the entire previous school year revealed a range of 2-20.5 days absent for children from separated or divorced homes. The days absent included 2, 2, 2, 2, 3, 10, 16, 16.5, and 20.5. The days tardy from the entire previous school year were $0,1,1,1,2,4,6,18$, and 18. Academic averages ranged from $94.43-99.71$ in the group from continuously married two-parent homes with one at 94.43, one at 95.80, five at 96.42-96.99, three at $97.00-97.99$, and one at 99.71. For the children from separated or divorced homes, academic averages ranged from $90.57-96.87$ with six falling at 93.00 or below and two above 95.00. The results of this sample supported the idea that children from separated or divorced homes will obtain lower academic averages than children from continuously married two-parent homes. The available 2002 Spring Stanford Achievement 9 test scores revealed the following national percentiles for children from continuously married two-parent homes: $26,52,60,64,66,68,71,75,82,82,89,89,90,96$ with a mean of 74.64. The 2002 Spring Stanford Achievement 9 test scores revealed the following national percentiles for the children from separated or divorced homes: $39,56,67,73$, $77,78,82,87,89$ with a mean of 71.56 . By dropping the lowest score from each group, the children from separated or divorced homes had a mean of 76.13, and the children from continuously married two-parent homes had a mean of 75.69. By eliminating the top and bottom score of both groups, the mean for children from separated or divorced homes was 74.28 while the mean for children from continuously married two-parent homes was 74.00 . 
Each group of students was given the Child Rating Scale (CRS) (Alpert-Gillis, 1989, p.583) measuring the child's perceptions of school problems and competencies based on rule compliance, anxiety/withdrawal, social skills, and self-confidence in September and again in December. The child rated twenty-four statements as "usually yes," "sometimes," and "usually no." "Usually yes" equals 3 points, "sometimes" equals 2 points, and "usually no" equals 1 point. The higher the score on the Child Rating Scale, the stronger the sense of well-being was for the child. Descriptive statistics are displayed in Tables 7, 8, and 9.

Table 7: September Scores - Child Rating Scale (CRS)

\begin{tabular}{|l|l|l|l|l|l|}
\hline Group & Mean & SD & N & S.E. Mean & Range \\
\hline experimental & 46.13 & 4.79 & $8^{*}$ & 1.70 & 13.00 \\
\hline control & 45.19 & 4.20 & 16 & 1.05 & 17.00 \\
\hline
\end{tabular}

*Scores unavailable for a $2^{\text {nd }}$ grader and a $5^{\text {th }}$ grader.

Table 8: December Scores - Child Rating Scale (CRS)

\begin{tabular}{|l|l|l|l|l|l|}
\hline Group & Mean & SD & N & S.E. Mean & Range \\
\hline experimental & 46.13 & 3.80 & $8^{*}$ & 1.34 & 11.00 \\
\hline control & 45.56 & 4.68 & 16 & 1.17 & 18.00 \\
\hline
\end{tabular}

* Scores unavailable for a $2^{\text {nd }}$ grader and a $5^{\text {th }}$ grader. 
Table 9: Changes in CRS from September to December

\begin{tabular}{|l|l|l|l|l|l|}
\hline Group & Mean & SD & N & S.E. Mean & Range \\
\hline experimental & 0.000 & 5.45 & 8 & 1.93 & 18.00 \\
\hline control & .375 & 3.61 & 16 & 0.90 & 16.00 \\
\hline
\end{tabular}

Tables 7 and 8 show that both in September and December, the children from separated or divorced homes respectively scored 0.94 and 0.57 higher than children from continuously married two-parent homes. Table 9 reveals that no change was present in the mean scores for the experimental group. The mean for children from continuously married two-parent homes increased by .375 points during the time period.

The researcher was interested specifically in possible gains or losses in the $4^{\text {th }}-$ $6^{\text {th }}$ grade group. Tables $10-12$ display the data.

Table 10: September Scores - Child Rating Scale $4^{\text {th }}-6^{\text {th }}$ Grades

\begin{tabular}{|l|l|l|l|l|l|}
\hline Group & Mean & SD & N & S.E. Mean & Range \\
\hline experimental & 43.40 & 2.70 & 5 & 1.21 & 6.00 \\
\hline control & 44.80 & 5.01 & 10 & 1.58 & 17.00 \\
\hline
\end{tabular}

Table 11: December Scores - Child Rating Scale $4^{\text {th }}-6^{\text {th }}$ Grades

\begin{tabular}{|l|l|l|l|l|l|}
\hline Group & Mean & SD & N & S.E. Mean & Range \\
\hline experimental & 44.60 & 1.52 & 5 & 0.678 & 4.00 \\
\hline control & 46.00 & 4.92 & 10 & 1.56 & 18.00 \\
\hline
\end{tabular}


Table 12: Changes in $4^{\text {th }}-6^{\text {th }}$ Grade CRS from September to December

\begin{tabular}{|l|l|l|l|l|l|}
\hline Group & Mean & SD & N & S.E. Mean & Range \\
\hline experimental & 1.20 & 2.28 & 5 & 1.02 & 6.00 \\
\hline control & 1.20 & 2.15 & 10 & 0.68 & 7.00 \\
\hline
\end{tabular}

Tables 10 and 11 show that both in September and December, the children from continuously married two-parent homes scored 1.40 points higher than did the children from separated or divorced homes. Table 12 shows that both the experimental and control groups gained a mean of 1.20 points during the time period. From this data, the researcher concluded that both groups of $4^{\text {th }}-6^{\text {th }}$ graders were similar in their sense of well-being.

\section{Initial Parental Input}

At the beginning of the project, a letter giving information about the peer-support groups (Appendix P) and Parent Evaluation Forms (PEF) were sent to parents of the ten participating children from separated or divorced homes. The PEF used a four point Likert scale including the choices of "very true," "somewhat true," "not very true," and "not true at all." Twenty-four statements were made regarding the child, and the parent responded with the scale. The topics for statements included the parent's perception of how well the child gets along with peers and family, the child's communication skills, the child's current emotional conditions, and the child's problem-solving skills. Totals were 
gained by adding the numbers circled. The higher the score, the stronger was the parent's perceived adjustment of the child. In each case involved in the current study, the mother was the custodial parent. Six of the ten mothers completed and returned the forms.

All responding mothers indicated that their child gets along well with other children, was generally happy, and was doing well in school. Two parents indicated that their child struggles with worry. A varied response ranging from "very true" to "not very true" was given regarding the child's attempts to solve his own problems. Four indicated that their child is easily upset. Two parents indicated that their child keeps feelings to himself, and two others chose "somewhat true" for this statement. Five indicated that the child worries about the family to some degree. Three cited anger as a potential problem. Three selected that their child does not express feelings appropriately. Two indicated that their child has a low self-concept. Four felt that the child demands much attention from the parent. None of the parents indicated that the child felt responsible for family problems. Four indicated that the child was unable to distinguish between problems he can and cannot solve. Information gathered from the PEF will be later contrasted with the perception of the children given in the Child Family Adjustment Scales.

\section{Initial Child Input}

Nine of the ten children from separated or divorced homes completed a Child Family Adjustment Scale (CFAS) form at the beginning of the project. This form complemented the Parent Evaluation Form and gave the child's perspective on the same topics. The CFAS contained 16 statements which the child rated as "No," "Sometimes," 
and "Yes." Seven of the nine children indicated that they feel very sad when they think about their family and that they worry about their family. Four children worried specifically about who will take care of them. All of the children indicated that their feelings were "o.k. to have" and that they could discuss their feelings with their parents. They were divided about problem-solving abilities. Two felt confident in thinking of ways to solve problems, three felt that they could sometimes solve problems, and two did not feel that they could think of ways to solve problems. In responding to the statement, "I worry a lot," four selected no, four selected sometimes, and one selected yes. Three were concerned that bad things might happen to them. Five were afraid to be left alone, and four were not. Four sometimes worried that their parents might leave them, and five were unconcerned about this. Six indicated a problem with anger. Three sometimes felt that problems at home were their fault, and six did not. In responding to "I feel good about me," five selected yes, and four selected sometimes.

\section{Initial Teacher Input}

Classroom teachers of the ten children from separated or divorced homes completed a Teacher-Child Rating Scale (T-CRS) which was on a five point Likert scale ranging from "Strongly Disagree" earning one point to "Strongly Agree" earning 5 points. A higher overall score indicated better adjustment. The T-CRS measured the child's classroom adjustment in areas including acting out, anxiety, learning problems, frustration, tolerance, assertiveness, peer social skills, and task orientation. As a group, the ten children received high ratings in overall classroom adjustment. Nine children received "strongly disagree" in the areas of being defiant, withdrawn, or overly 
aggressive. Seven received "strongly disagree" in the areas of nervousness, trouble interacting with peers, and avoided by other children. Eight did not lack social skills while two received "strongly agree" to the statement that social skills were lacking. Nine functioned well with distractions, and one received "strongly disagree." Nine were liked by classmates. Areas in which scores were scattered across the Likert scale included "disturbs others while they are working," "accepts imposed limits," "makes friends easily," "defends own view under group pressure," "has poor concentration or limited attention span," "does not express feelings," and "comfortable as a leader." One child, however, consistently scored differently than the others. According to the T-CRS, he disturbed others while they were working, lacked social skills with peers, had difficulty following directions, did not easily make friends, did not function well with distractions, did not cope well with failure, had limited attention span, and did not have many friends. This child was also the one who missed the majority of the younger group's support sessions during the project. The other nine appeared well adjusted in their classrooms.

\section{The Heart of the Project}

Without a doubt, the heart of the project existed in the eleven weekly meetings of the six $4^{\text {th }}-6^{\text {th }}$ grade students from separated or divorced homes led by the researcher and another teacher. The group evolved from eight individuals who were somewhat apprehensive about sharing intimate thoughts with a group of acquaintances into a tightly knit group who could freely share the most personal thoughts and concerns with the assurance that confidentiality would be maintained by the group. The students are to be applauded for their increased trust, empathy, and encouragement with their peers. 
Because the setting was a Christian school, ideally, the curriculum should present biblical views. No distinctly "Christian" curriculum was found. The curriculum designed and published by the Children of Divorce Intervention Program (CODIP) did not contradict biblical ideas about character, values, and problem solving. Biblical principles could easily be applied to the curriculum.

When the original group of seven first met, students conducted interviews regarding interests and family structure with another member and introduced one another to the rest of the group. An attempt was made to name the group based upon commonalities. After several weeks, the students had simply adopted the name "Group." The sixth student joined the third week. In preparation for including the newest addition, the researcher mentioned in week two that another student would like to join Group. Without knowing the identity of the newcomer, one student's response was, "Hey! The more the merrier!" The newcomer's parent had desired for him to join the group, but because the student was reluctant to join, he had not returned the paperwork. The omission was discovered by a classroom teacher and the parent. Interestingly enough, when that same student had to miss a subsequent session, he told his mother, "You realize you made me miss Group today." He was genuinely disappointed to miss, and his mother was thrilled with the change in his attitude.

JoAnne Pedro-Carroll's Children of Divorce Intervention Program was the curriculum implemented. In their first week, the students completed initial paperwork 
including a "Problem Checklist" provided by the curriculum, a "Child-Rating Scale" measuring well-being, and a "Child-Family Adjustment Scale" measuring attitudes regarding families. The "Problem Checklist" gave 22 possible problems the student might encounter. The students checked the ones that are current problems for them personally and put stars by the ones that bothered them the most. The most common problem identified by four of the six students was "I have a hard time getting my homework done." "Dad is angry a lot" and "We don't have enough money for movies and other fun like we used to" both tied for second place and were identified by three students. Two students identified each of the following as problems: "Dad doesn't have enough time to spend with me;" "Mom is angry a lot;" "I sometimes think it was my fault that my parents got divorced;" "I sometimes don't think Mom wants me around;" "I have a hard time doing my household chores;" and "I don't get along with my friends as well as I used to." Each of the following problems was identified by one student: "Mom doesn't have enough time to spend with me;" "I am angry a lot;" "I am always thinking about my parents;" "I had to move away from my friends;" "I don't like the men Mom goes out with;" "My Mom is always telling me to say or do things to Dad that I don't want to;" and "I have a lot more trouble in school than I used to." Problems receiving stars signifying the severity of the problem included not enough time with Dad, an angry Mom, personal anger, not enough money, disliking the men Mom dates, thinking that Mom doesn't want me around, and not getting along with friends as well as before. Identification of these concerns provided insight into the personal worlds of the students and allowed their concerns to be incorporated as topics in the sessions that followed. 
Pedro-Carroll's curriculum for fourth through sixth grade contained two major segments: focusing on feelings and enhancing coping skills. The curriculum was the basis for the content of the group sessions. Some modifications were made to make a better fit for the group. The first three weekly sessions were directed toward feelings. Initially, simply identifying and defining feelings was a goal. From a grab-bag students selected a slip of paper containing a feeling and could choose to either pantomime it or select a different slip to act out. The others in the group had a reference chart with the feelings listed and attempted to guess the performance. The researcher took the first turn, and volunteers followed. Everyone participated, and support of one another began. As we became better acquainted, the atmosphere became more relaxed. One boy chose one of the final slips from the bag and was struggling with an idea. The researcher looked at the feeling listed and agreed that it was a difficult one. "Silly" was tossed open to the entire group. The girl who had been the most quiet and reticent throughout the activity softly said, "I can do a really good silly." The group jumped at the opportunity for her to volunteer and encouraged her to demonstrate. She was able to dimple her tongue while making a funny face. Everyone applauded her demonstration, and she began to gain some confidence in her contributions. Sometimes children struggle with feelings associated with separation and divorce and are unable to identify the feelings so that they can begin to deal with them. The initial activity began the process of discovering and defining emotions. Attitudes regarding separation and divorce were also explored. Students were initially unwilling to share their thoughts regarding divorce. The researcher postponed that conversation for a later week's session. In the first session, confidentiality was explained. Students agreed that they could share anything they personally said or 
learned with a parent, but anything shared by another member of group should remain in the group itself. Each individual could decide whom to tell what he shared during a meeting.

The next two sessions expanded the understanding of emotions to include the idea that feelings are individual and can change. Causes of feelings were also explored. Clarifying commonly held misconceptions regarding separation and divorce was the new focus. The curriculum called for the use of filmstrips "When Parents Separate" and "After the Divorce" for the second and third sessions. Both filmstrips are no longer available. When contacted by the researcher by e-mail, CODIP sent an updated list of books with copyrights from 1995-2001 as resources. Because students were hesitant in the first session to share their personal feelings about divorce, the researcher elected to use Krementz's book How it feels when parents divorce. In the book, children ranging from ages 6 to 18 tell their personal stories about experiencing the divorce of their parents. A full-page picture of each child is included at the beginning of each chapter. While the book is dated 1984, the stories proved to be relevant. The researcher read the story of a particular child while the students listened and studied the picture of the author. The group began to apply their understanding of feelings to divorce situations. While students were initially unwilling or unable to share their personal experiences and feelings regarding divorce, they had no problem discussing the feelings and problems of the child-authors in the book. It was common for a child to say, "I know exactly how they feel," identify the feeling, its cause, and then follow with a personal example. The number one revelation that came from this session was "Divorce is not the kids' fault!" 
Other issues included living in two households, finding out about the separation, being used as a messenger, separation from friends and family, taking sides, blame, leaving a pet behind, keeping up with school work, trying to get parents back together, and other challenges children face when living in a divorced home. Students willingly addressed the child-authors and one another with what has or has not worked for them. In the sessions that followed, students were eager to hear from "more kids in that book."

The final fifteen minutes of group were spent focusing on positive traits of individuals. As a group, students listed "what I've done right" and "good stuff" about themselves. They discussed their personal value based on being created in the image of God. They chose a positive attribute that could be used with each letter of their first name and began to create a design. Students continued talking while drawing. The researcher stumbled upon an effective technique. For each subsequent session, markers and paper were available for students to doodle if they wished during discussions. Students usually chose to draw during discussions. As they listened or spoke, they had the option of looking directly at a person or diverting their eyes to their own drawing. The option of doodling provided a safer and more comfortable atmosphere in which to share. Some weeks, the paper provided was designed to complement the discussion. For example, when the topic was making "I-statements" when angry, the paper was cut into large capital I's for that day.

In the fourth session, the focus shifted from talking about feelings and problems to doing something about them. An emphasis was that everyone has problems, not just 
kids whose parents divorce. The group listed possible problems and scenarios that anyone in fourth through sixth grade might have. They identified feelings that accompany the specific problems mentioned. The researcher introduced the five problem-solving steps included in Pedro-Carroll's curriculum:

1. Understand/identify the problem. Ask: What's the problem?

2. Generate alternatives. Ask: What are all the things I could do, and what else could I do?

3. Consider the consequences of alternatives. Ask: What might happen next?

4. Choose the alternative that looks best. Choose one and try it!

5. Self evaluation and reinforcement. Ask: Did it work? (Pedro-Carroll, 1994, Session 4).

The group then took turns choosing a problem to take through the five problemsolving steps. They thoroughly enjoyed brainstorming all possible solut ions without regard to consequences. Together, they placed a plus or a minus beside possibilities in step 4 as they considered "what might happen next." A consideration included in considering consequences was whether or not the choice would please God. The "homework" for the next week was to write down one problem they would like the group to tackle in the next session.

Session five began with a review of the five problem-solving steps. Students wrote down scenarios for discussion and gave them to the researcher. The researcher read the scenarios and put them in a grab-bag which contained other scenarios suggested by the curriculum. Scenarios provided by students are as follows:

1. It's Friday. You want to play, but your book report is due Monday. 
2. You have a huge state report to do, and you don't want to do it.

3. You want to finish watching a television show you started, but it isn't over before you have to go to bed.

4. You fight with your brothers or sisters because your parents are separated and you are really disappointed.

5. You can't get to sleep at night because you are thinking too much about your family.

6. Your mom smokes, and you want her to quit.

The researcher reserved problem 6 for the next week. Students were eager to take a turn selecting a slip from the bag. Together, the group practiced applying the problem-solving steps. An additional twist to the activity was the opportunity to role-play solutions. Four students were eager actors, and two preferred to be an audience. The "homework" was to actually attempt to apply the problem-solving steps in a real situation some time during the week and to be ready to share in the next session.

Session six began with one student excitedly sharing her application of the problem solving steps. She and a step-sister had a disagreement. Rather than immediately reacting, the student applied her skill with the problem-solving steps and was able to resolve the problem in a manner that pleased both her and her step-sister. The group applauded her success! Other members did not have stories to share at this time but were encouraged by her example to actually give the problem-solving technique a try. 
This session's new focus was distinguishing between solvable and unsolvable problems. Even though the group was becoming quite adept at solving problems, some problems exist that we cannot completely solve. We began with example 6 from last week: Your mom smokes, and you want her to quit. The group attempted to apply the problem-solving steps. They concluded that while you could tell your mom you love her and want her to stop, you could not force her to quit. Students listed other problems that they could not personally solve. The group then looked for similarities in these problems. They determined that if another person's decision was involved, then you could not solve the problem for them. We applied this truth to scenarios involving divorce. For the first time, some students realized that they could not get their parents back together because that is a decision the parents had to make. So what can a child do if he encounters an unsolvable problem? Disengaging from the problem was the answer given in the curriculum. Students brainstormed ways to disengage. Their ideas included spending time with friends or a pet, writing in a journal, participating in sports or doing something else they enjoy. The curriculum recommended disengaging by working on problems that they could solve. A grab-bag of divorce-related scenarios was then used. Students selected a scenario from the bag and attempted to determine if it was solvable or unsolvable. If it was solvable, the group took it through the five steps. If it was unsolvable, the group role-played disengaging from the problem. As the session concluded, preparation was made for the next week's activity: Panel of Experts. Much had been discussed in the first six weeks. Next week would be a grab-bag of questions reviewing what we had discovered together. The group members would take turns being experts providing advice for the rest of us. The group was excited about this opportunity. 
Session seven's "Panel of Experts" solidified previous discussions. Students were eager to take their turns being the "experts." Most of the questions in the grab-bag were generic and were provided in the curriculum. A few questions pertaining to concerns that had surfaced in the group were added by the researcher. This activity gave students an opportunity to share some personal concerns in addition to reviewing skills. The following sampling of student replies gives the flavor of this session and a glimpse into the heart of the students. The question was, "Is it better not to tell anyone if your parents are divorced? Why or why not?" A student responded, "I think the worst two things a kid can do is think it's your fault and keep it bottled up inside. You've got to talk to someone - a friend, maybe a kid whose parents are divorced.” Another question was, "Do kids whose parents are divorced some times have more trouble at school? Why or why not?" The response was, "Yes. They have too much on their mind. If parents live in separate places, a kid can forget his homework at the other house." Students generated possible solutions for organization. They agreed that always putting homework and books in their backpacks was one way to stay organized. Another question was, "Can kids get their parents back together if they try really hard?" The student initially responded, "I think I could if I had all the facts." Then he paused, thought a minute, and said, "No. It's not my problem, and it's not my fault. I can't fix it." The question was, "When parents begin to date, does this mean that they no longer love their kids in the same way?" One student replied, "No, they still love you. My dad lived with someone for two years. They had been married for three months before he told me. He said it 'slipped his mind.' I think that's a kind of funny thing to have slip your mind." The question was, "Should parents 
NOT get a divorce until their children are grown-up?" The student replied, "That's a grown-up problem. Kids shouldn't have to deal with it. If they're going to keep fighting, they should get divorced." The question was, "Can kids from divorced families be just as happy as kids whose parents are still married? Explain.” A difference of opinion existed here. "Happiness is a personal choice" was one answer. Most students shook their heads indicating "no." One student who lives with his mother related the following story. "No, I don't think so. I was taking the trash out, and I saw a dad with 2 kids on his motorcycle riding by. I got emotional. It was hard for me to take.” Some questions evoked very personal responses. Students listened carefully to one another and would sometimes offer possible solutions or would quietly empathize. This session tightened the bonds of the group. Students requested a repeat of this activity some time in a future session.

Because only four sessions remained, we began the group-ending process to prepare students for yet another change in their life. Index cards were given for students to write any special issues or divorce-related concerns they would like to discuss in the remaining sessions.

Sessions eight and nine focused on handling anger. Identifying causes of anger, feelings of anger, and finding appropriate ways to express anger were the goals. Productive versus destructive methods were discussed. If it made the situation better, it was productive, and if it made the situation worse, it was destructive. Students generated productive ideas for handling anger. The students' productive ideas included cooling down before you talk, writing a letter to the person and not mailing it right away, writing 
in a journal, asking God to help you, talking to a trusted friend, talking to a pet, taking a walk, trying to see it from the other person's position, reading a book, running, sports, and using up your extra energy in homework or chores. Learning to use "I-statements" rather than "You-statements" was the skill the group tackled. "I-statements" involve telling the person how you feel rather than accusing them. "I feel this way when a particular thing happens..." The "I-statement" is followed with a request for a change. Students practiced making "I-statements" and asking for a change that might bring a solution. The group then generated anger-provoking scenarios, most of which were divorce related, and role-played handling them in productive ways. Session nine concluded with the group planning the final party for session eleven. They wanted to answer more questions like we did in session seven and role-play the answers. The group selected ice-cream sundaes for the celebration.

Session ten began with the necessary concluding paper-work for the project. Students completed a second "Child-Rating Scale" which was later compared with the initial ones they filled out in September. They completed an evaluation that was included in the curriculum and a final questionnaire developed by the researcher (Appendix J). The researcher prepared twenty-one questions for discussion (Appendix K). Some of the questions were the concerns students had expressed on their final index cards. Other questions were developed from the questionnaires the students had answered at the beginning and ending of the project. Areas of concern indicated by students on their initial "Problem Checklist" from CODIP were included in the questions. Several questions were simply pertinent topics the researcher chose for discussion. In the 
remaining time of session ten, students drew questions from the grab-bag. The group discussed and role-played their answers. Following session ten, the researcher wrote a personal note to each student inviting them to the final session and party.

Session eleven began with ice-cream sundaes and Vanilla Coke. Students drew questions from the grab-bag, and we discussed and role-played as we munched. The following is a sampling of questions and student answers that were given. "Why did God let my parents become separated or divorced?" The students answered that people are sinful and are not robots. People make choices. It's not God's fault any more than it's the kids' fault. Another scenario was, "My dad is doing something special without me, and I feel really left out. What can I do?" Students chose to use "I-statements" and to request a change. They role-played this scenario. Another scenario that came from a student's index card was "Sometimes I feel like my parents would rather not have me around. This really hurts. What can I do?" The group chose to talk to the parents about their feelings. A second option they generated was to talk to their grandparents. A question which originated from an actual situation one student experienced was the following: "I just found out that the parents of one of my good friends are getting a divorce. How can I help my friend?" Passionate answers flooded this question. "Tell her it's not her fault." "Tell her about our group, and maybe she can come." "Listen to her whenever she needs to talk." "Tell her you've been through it, and she'll be o.k." "Tell her not to take sides." Another question for which students had much advice was "When I grow up, how can I be sure that I am marrying the right person so we won't end up divorced?" "Be sure to pray about it." "Spend a lot of time with the person before 
you marry them to be sure you like each other." "Ask the person if divorce is an option for them. Tell them it isn't an option for you. Don't marry them if divorce is o.k. with them." "Work really hard on your problems." "Ask your parents what they think about the person." A question from the grab-bag that soon followed was "Because my parents were separated or divorced, does that mean that when I grow up and get married that I will also probably get separated or divorced?" One student answered this question affirmatively stating that kids learn from parents and might follow their example in divorce. Other students emphatically stated, "No." One said, "I'm another person. I can make my own choices." Another response was, "No way. You just need a strong relationship with the person and with God." The final question we discussed was "Once our group quits meeting every Tuesday, if I have a problem I want to talk about, what should I do?" We agreed that any group member could come and talk or write to any other group member or leader at any time. If we felt the need to get back together, we would do it.

To close our group, each student was presented with a journal that included an encouraging, personal note thanking the student for participating from the researcher and another from the second teacher involved in Group. The group prayed together and then dispersed knowing that we are not alone and could reconvene if needed. 
Chapter IV: Perspectives, Conclusions, and Recommendations

Four groups of "stakeholders" were involved in this project: the teachers, the parents, the students, and the researchers. Perspectives and conclusions from each group will be disclosed.

\section{Perspectives and Conclusions of Teachers}

Questionnaires (Appendix L) regarding their classroom experience with divorce in the Christian school setting were given to the thirteen $\mathrm{K}-4-6^{\text {th }}$ grade elementary teachers at the Christian school in Northern Kentucky that sponsored the project. The eight teachers who responded have been teaching for the following number of years: 5,8 , $8,8,13.5,15,16$, and 35 . Their responses will be shared.

Question: “Are you usually aware when students in your class come from separated or divorced homes? How do you gain this information? Would it help you to know which students are from separated or divorced homes?"

The teachers indicated that they usually are aware when students are from separated or divorced homes. Longevity in the same school allows for some knowledge of families. Others gain information from the students themselves or directly from parents. Some say that last names are indicators and that it helps to know last names of each parent. The teacher of 35 years states that sometimes she knows, and sometimes she does not. All teachers indicated it would be helpful to have this information before 
school begins to better help the student and to avoid embarrassing situations of using incorrect names. Two teachers gain information at the beginning of the school year by giving their students a questionnaire asking "Who do you live with?"

Question: "In your experience as a teacher, has family separation or divorce affected students in the classroom setting? If so, explain what you have observed."

All teachers answered affirmatively. Emotional effects such as sadness, crying, anger, aggression, withdrawing, and fear were mentioned. Sometimes students act as if nothing is wrong. Younger children may become clinging to the parent or teacher. One teacher shared that a first grader sat weeping on the floor of the classroom saying, "I don't know if I'll ever see my daddy again." Delayed communication and late work were also mentioned.

Question: "In your experience as a teacher, has family separation or divorce affected your communication with parents? If so, please explain.”

Seven teachers answered affirmatively. Sometimes, one parent has custody, and the communication is limited to the one. Other times, two copies of every communication need to be made so each parent receives information. Conferences can be strained. Parents sometimes desire separate conferences with teachers and other times will share a conference. Determining what to call a parent can be a challenge. 
Restraining orders against a parent can complicate the situation. Class parties and field trips with chaperons have the potential to become awkward.

Question: "What strategies have you used to help students from separated or divorced homes in your classroom?"

Answers included none, lots of prayer, extra hugs, more patience, keeping a routine, tutoring, and being available to the child. One teacher shares her own struggles through her parents' divorce with students experiencing divorce. Another gives extra time to complete assignments that were left at "the other parent's house." She cautions that creating a balance between responsibility and understanding is needed. Creating a safe environment at school is recommended. A teacher of younger children includes different structures of families when discussing "family" with her class and assures students that both parents love them.

Question: What advice do you have for other teachers who are working with students experiencing family separation or divorce?

Being available to listen to students, being consistent in love and discipline, praying for the family, recommending a counseling service, never taking sides, and being flexible with the student were suggestions that were given. 
Following the eleven weekly sessions, two teachers mentioned that they had observed positive changes in two of the six students participating in the fourth-sixth grade support group. The two students were more actively participating in class and appeared to be more positive and cheerful. Teachers of the other four students in the fourth-sixth grade support group noticed no changes in the students following the support groups. No changes were noticed by teachers of the students participating in the Kindergarten-third grade support group. One possible reason for the lack of change is that most of the students were already well adjusted in a classroom setting.

\section{Perspectives and Conclusions of the Parents}

A final letter (Appendix N) and questionnaires (Appendix M) for parents in sealed envelopes marked "confidential" were given to the students participating in the support groups in week 9. Return envelopes addressed to the researcher and stamped "confidential" were enclosed. Students were promised a candy bar (of their choosing) when they hand-delivered the completed questionnaire to the researcher or another group leader. Eight of the ten questionnaires were completed and returned.

Parents indicated that their child's basic attitude toward attending the support groups was positive. One parent mentioned that her son initially did not want to attend the group, but after attending two sessions, "he really enjoyed it!" Another comment was that the child "truly loved the support group" and was very upset when he had to miss a session. One child whose parents were in the separation phase experienced a variety of attitudes. The mother explained that the child was uncertain at first. Then she enjoyed 
group. A little later into the sessions, she cried about going. For the last four sessions, she really wanted to attend. Other parents indicated that their children had "no complaints about attending" and were "very willing to go."

Parents shared what their children told them that they had learned or had experienced in the group. The only comment from the younger group was that one child shared how parents become divorced. They "go to court." From the fourth-sixth grade group, two parents mentioned that their children discussed basic details of the meetings with them. Another parent stated that her daughter would usually tell topics that were discussed but would not share what she had personally learned. The same mother disclosed that the "acting" was her daughter's favorite part of group. The mother whose separation is the most recent shared that her daughter verbalized that the separation is not her fault. The mother stated that the parents have repeatedly told her this in the past, but the fact seems to have "sunk in more with your group." Another parent voiced that while she and her son "have discussed several things from this group, what I noted the most was his acceptance that he could not change things."

Parents were asked if they had noticed any changes, either positive or negative, in their child in association with the groups. The members from the younger group and two from the older group noticed no changes. Another parent shared that her daughter was positive about how the group could help others. She "wanted to invite a friend whose parents are divorcing right now and hoped it would help her." The mother of the child whose feelings about group fluctuated explained that her daughter's perception was that 
she had "been laughed at." The mother stated that the daughter later realized that this was not the case and she was once again very positive about group. A parent of a boy shared that while she is uncertain whether this change is related to group or not, "he has been more willing to help out without complaints and is taking on responsibility for himself without my encouragement.”

Parents were asked how classroom teachers could better assist them and their child in regards to separation or divorce. One response was, "If for some reason the child acts different or seems to be troubled, let the parents know or see if anything is going on at home." A similar response was, "Try to be attuned to feelings and behavior. Sometimes children make comments to the teacher that give insights into how they feel, but the child doesn't tell the parent. Keep communication open." Another response was, "I was surprised when both of my children's teachers seemed unaware of our marital separation even though the paperwork at the beginning of the year documented this." A parent whose child attended the group but whose two step-children did not attend stated, "The worst struggle for my step-children has been living in two homes. They have the added responsibility of remembering to take things back and forth. If teachers are aware of this situation with other kids, be understanding of the possibility of forgetting something at the other parent's." A final response was, "The best or most helpful thing that I can say is to be understanding that these children do not have the same support that kids with two parents have. Many times, things don't get done because of that. Many times, my son has gotten into trouble at school for something I forgot." 
When asked how the school could better assist their families, four parents had no suggestions. Offering support was a theme of other answers. One response was, "I believe that having support, should you need it, is a must." The kind of support was not identified. Another parent clarified by saying, "Be supportive. It can be very difficult both emotionally and financially to go through these times." A third response was, "Being a single parent, money is always tight. A program for hand-me-down uniforms would be great. It would also be helpful to not have so many half days because it is hard to find people to pick my son up early." Another response was, "I think it would be of great benefit to kids if there were someone qualified to listen and share this progression of time with the kids or kids with each other in group settings where they realize they're not alone. Some of the kids have adjusted well while others are just beginning this painful journey."

The final question asked of the parents was "In your opinion, was the group experience beneficial for your child? Please explain." The mother with two sons in the younger group responded, "I'm not really sure, but they sure did enjoy going!" The mother of the other boy in the younger group responded, "Yes. He was able to see that he's not the only one in his situation." From the older group came the following responses: "Yes. The timing was good in conjunction with her counseling, and it allowed her to see there were other children in similar situations." "Yes. I think this would help any child in how to express their feelings and handle problems." "I think so. He wishes the experience was still ongoing!" "Very much so. Many times he voiced looking forward to group. I think it helped him feel not so different after all." "I think 
so. I didn't know if my daughter would want to share with others about all this but am glad she wanted to do this. I think it always helps to know there are others like her and not to feel like you're the odd one out. Hopefully they'll never be a majority, but this was good!"

\section{Perspectives and Conclusions of the Students}

Two questionnaires were given to the six students in the fourth-sixth grade support group in the tenth week. One form (Appendix J) was designed by the researcher, and the other was provided in the CODIP curriculum.

The researcher's final questionnaire began with requesting the age of the child when their parents separated or divorced. Three of the participants were $1 \frac{1 / 2}{2}$ years or younger. One was 3 years old, one was six, and another was eight. For all children except one, the separation or divorce had occurred five years or longer in the past.

The question "How did your parents explain to you that they were separating or divorcing?" was asked. Separation was never explained to three of the participants due to their young age. The following are the responses of the others in the group. "Things weren't going well." "They couldn't be together because they weren't getting along."

“They told me my dad wasn't going to live with us any more and was going to live at my grandma's house." 
Participants were asked what has been the hardest thing for them about the separation or divorce. The following responses were given. "Being an older brother and my temper." "My dad not living with us any more." "I have a hard time sleeping at night." "Not seeing my dad that much." "Not getting to see my dad as much." "The custody."

When asked if they ever have the feeling that the separation or divorce might be partly their fault, three responded with "No," and three responded with "Yes."

The question was, "What is the most important thing you've learned from the separation or divorce?" Four responded that the most important thing to them is that the separation or divorce is not their fault. One replied, "Don't take sides." The final one wrote, "I thought I was losing a dad, but I really was not."

Participants were asked for their advice for parents who are considering separation or divorce. The following responses were given. "Stay calm." "Keep it off your mind." "Make sure the kids know about it." "Tell your kids it's not their fault." "Don't put pressure on the kids." "Think of what it does to the kids."

Participants were asked for their advice for kids whose parents separate or divorce. The following thoughts are their advice. "It's not your fault." "Still try to have fun." "Don't think it's your fault." "Talk to your parents about how you feel." "Don’t take the blame." "Don't think it's your fault." 
Advice from the group members to teachers was solicited. "Tell the kids to stay calm." "Try to explain that their parents just didn't work out." "Explain that it's not their fault." "Tell them it's not their fault." "Pray for them and try to help as best as you can." "I don’t really know."

The final question was, “Does your parents' separation or divorce still affect you? Explain." One stated "No." Another wrote, "Maybe, sometimes." Other responses included the following. "Not really. I'm getting over it." "No. Because I am used to it." "Sometimes my mom yells at my dad on the phone and my dad yells at my mom so then I think just sometimes that it's my fault." "Yes. My parents have basically been divorced all my life. The good thing was that I got to come to school here at CCS."

The first question on the CODIP form inquired of the participants what were the two or three most important things that this group has meant for them. The member whose parents' separation was the most recent and whose feelings about group fluctuated throughout the eleven weeks responded, "It has helped me understand that it's not my fault my parents separated. It's been really fun. It's helped me talk to my parents more than I usually do." A second girl responded, "It has helped me a lot. Now I can solve problems. I feel much better." A sixth grade girl responded, "It has helped me to show my feelings and to stand up for what I have to say." Another sixth grade girl responded, "Learning and acting." A fifth grade boy mentioned, "Role playing and talking about problems." The other fifth grade boy replied, "Someone to talk to; getting ideas; fun!" 
The question about what changes they would make in group was posed. Four responded with "Nothing." The fifth responded, "Not really anything; I think it's fine." The sixth stated, "People not being here." Some weeks, a member was absent, and the group was not "complete" without everyone present.

The final six questions on the CODIP form were statements that participants rated on a Likert scale including "very true," "sort of true," "not very true," and "not true at all." The statement concerning making some new friends in the group was "sort of true" for four students, "very true" for one student, and "not very true" for one sixth grade girl. Learning new ways to solve problems was overwhelmingly "very true" for the group. Only the same sixth grade girl previously mentioned selected "sort of true" for that statement. The statement that "being in the group helped me to understand my feelings better" was once again "very true" for five participants and "not very true" for the same sixth grade girl. For the statement "I feel less alone than I did before our group," three selected "very true," two selected "sort of true," and the sixth grader selected "not very true." The statement "People in my group cared about me and my feelings" was given a rating of "sort of true" by four members and "very true" by the other two. Interestingly enough, the sixth grader was one of the two who felt strongly that people cared about her feelings. The sixth grader chose "sort of true" when rating the statement that the group was a safe place to discuss personal feelings. The other five participants selected "very true" that the group was a safe place for them. 


\section{Perspective and Conclusions of the Researcher}

The past months of researching effects of divorce on children and establishing support groups in the Christian school setting has been a roller-coaster ride. Initially, the researcher was excited about the prospects of completing a quantitative study while assisting young people who may be struggling in their own personal lives. This prospect was dashed when many divorced parents chose not to allow their children to participate in the study and support groups. The two main hindrances were busy schedules of parents and children and having the support groups connected to a thesis study. Although the anonymity and confidentiality of the study were emphasized, more parents would be willing to allow their children to participate if their privacy were not threatened with a "thesis study." Hopes were renewed when two groups of four and six children were willing to participate. However, the idea of preparing a quantitative study capable of inference to the general population of children from separated or divorced homes in Christian schools was squelched by the inadequate sample size. The researcher struggled with what to do. The desire to continue delving into the chosen topic and the responsibility to the ten children and their parents who volunteered to participate were immense. Changing to a qualitative approach was the solution presented by the graduate study advisors. Personal involvement with the children while learning their thoughts and challenges and guiding them toward solutions was the most rewarding aspect of the project.

The author would like to invite other Christian schools to replicate this study so that the data might be aggregated and additional conclusions and treatments could be 
developed. Because of the difficulty of obtaining a large enough sample from one Christian school, value exists in numerous Christian schools conducting their own studies for comparison. If an official "study" is not performed, the author would like to encourage the initiation of peer support groups for children from separated or divorced homes in Christian schools. While parents may be reluctant to participate in an official "study," they are more likely to allow their children to participate in support groups led by Christian teachers.

A second grade teacher led the group of four kindergarten-third graders in their support sessions. The leader of the younger group summarized her experience of eleven weeks. "The first few sessions were very profitable. After that, students seemed to grow tired of the sessions and became somewhat silly during them. I would recommend beginning with 2 or 3 consecutive weekly sessions and then space other sessions out for once a month to have maximum benefit." She also noted that the age span of kindergarten through third grade was too great. The kindergartner was unable to participate and understand on the level of the older children. The CODIP curriculum recommended combining kindergarten and first grades in one group and second and third in another and actually had separate curricula for each age. We were unable to follow this directive because only one kindergarten child, a sibling of a third grader, would constitute the kindergarten through first grade "group." The parent strongly desired for both of her children to participate even if the kindergartner was "misplaced" with the second and third grade group. While we agreed to allow this for the initial group 
sessions, we would strongly recommend against combining kindergarten through third grade for future groups.

The researcher led the group of six fourth-sixth graders in their eleven weekly sessions. One common perspective presented in the previous literature review would expect the group of fourth through sixth graders to have no "issues" remaining from their parents' separation or divorce. As discussed in Chapter Two of this thesis, it is commonly believed that children usually recover from divorce in approximately two years. For five of the six children in the older support group, the divorce had been at least five years in the past. Three of the children could not remember a time when their parents were not divorced. Yet misconceptions and confused feelings about divorce were prevalent in the group. Struggles with living in two homes, feeling torn between two parents, guilt, anger, and inability to solve problems were common issues the children identified as current challenges in their lives. As a group, we were able to talk about their concerns and learn to problem-solve together. Members were encouraged by one another and by the knowledge that they are not alone in their struggles. The one sixth grader for whom the group experience seemed to be the most unnecessary due to her successful adjustment felt compelled to invite a close friend whose parents had just separated. In her mother's words, "She thought that Group would really help her friend." Because the timing was session ten in which members would be mostly filling out paper work and evaluations, the researcher did not agree to invite the girl at this time. Too much ground work in trust and confidentiality within the six original children might be jeopardized by including a new member as the group was concluding. The father of the friend later 
personally spoke to the researcher and said, "We've been told you are leading a class for kids who are experiencing the divorce of their parents. I desperately want my girls to be a part of this Christ-centered healing. I understand why they can't jump in at the very end. Please lead this class again and let me know when you do it. They will be there."

Are children in the Christian school setting affected by divorce and is there a need for Christian schools to provide support for these children? Absolutely! Are peer support groups effective in assisting the children experiencing divorce to thrive in a Christian school setting? From the perspectives of the teachers, parents, children, and researchers involved in this project, yes! Do the children themselves desire to participate in peer support groups? Please allow one group member's final question directed in the final session to the researcher to provide the answer. "Mrs. E., if you lead another class like this one, can we come?" 


\section{APPENDIX A \\ Teacher Release Form \\ Teacher/Group Leader Form}

\section{Please check the statements to which you agree.}

I am willingly participating in this study.

I will maintain confidentiality and anonymity of student information.

I release Calvary Christian School from any liability regarding this study.

Signature/Date: 


\section{APPENDIX B}

Explanation for the Executive School Board

The two-fold topic of my master's thesis for Cedarville University is the effects of divorce on children and what the Christian school can do to support the children of divorce. A major goal of the study is to offer assistance for children of divorce without giving offense to anyone. Between 20 and 40 families with children from Kindergarten to Sixth Grade are desired as willing participants. A confidential letter explaining the study and requesting interest and permission to participate will be sent to potential families. Attendance records and academic records will be examined. Participating children would attend 12-15 weekly support sessions with peers led by teachers for 45 minutes after school. Confidentiality would be maintained. The desired outcome is to support our children from divorced families and to help them thrive in the Christian school.

Prepared by Cheryl Ellington 


\section{APPENDIX C}

Initial Letter to Separated or Divorced Families

August 30, 2002

Dear Parents,

I am currently involved in a Cedarville University master's thesis study regarding the possible effects of separation and/or divorce on children and what Christian schools can do to offer support to the children. I am looking for 20-40 families with children in Kindergarten through Sixth Grade who would be willing to participate in the study. Reviewing school records such as attendance and academics would be included. Participating children would attend 12-15 weekly 45-minute support sessions led by CCS teachers after school. The sessions would be attended by peers (CCS children) from families that have experienced separation or divorce and would be divided into age groups $\left(\mathrm{K}-1^{\mathrm{st}}, 2^{\text {nd }}-3^{\text {rd }}\right.$, and $\left.4^{\text {th }}-6^{\text {th }}\right)$.

The goal is to foster support among the students and teachers and to assist the children in their adjustment and growth. Confidentiality would be maintained. Support sessions would be scheduled on Tuesdays from 3:45-4:30 p.m. We are hoping to begin in early September and conclude by Christmas break.

If you are interested and/or willing to participate, please complete the attached form and return it to your child's teacher or directly to me in the return envelope provided. Feel free to contact me for further clarification. If you would prefer not to participate, please check that information and return the form accordingly. Because we would like to begin early in September (possibly the $2^{\text {nd }}$ week), please return the form on Tuesday, 9-3-02. Mr. James and the Executive Committee of Calvary Christian School have granted permission for this study to occur.

Please prayerfully cons ider this opportunity. We would consider it a privilege to work with your children.

Sincerely,

Cheryl Ellington

Sixth Grade Teacher/Upper Elementary Coordinator

Calvary Christian School 


\section{APPENDIX D \\ Permission Form for Children from Separated or Divorced Families \\ Student Permission Form \\ (Please return in folder for 9-3-02)}

Participant's (Child) Name:

Parent's Name \& Phone Number:

Date of Birth:

Child's current age and grade:

Child's age and grade at time of separation:

Child's age and grade at time of divorce:

\section{Check List:}

Child's Background:

My child has attended only Christian schools beginning with Kindergarten My child has attended years at Christian schools and years in public schools beginning with Kindergarten Other (Please explain.)

Parents are currently separated.

Parents are currently divorced.

Child lives with parent who is remarried.

\section{Please check the following to which you agree.}

I willingly allow my child to participate in this study.

I understand that the study involves reviewing school records.

I understand that anonymity and confidentiality will be maintained.

I understand the project is part of a master's thesis.

I understand the study involves 12-15 weekly support sessions.

I would be willing to participate in a confidential interview.

I understand the support sessions in no way constitute psychotherapy or substitute for medical or psychological treatment.

My child is not currently begin treated for chronic, emotional difficulties. I understand that I may withdraw my child from the study at any time. I release Calvary Christian School from any liability in relation to this study.

Parent's Signature and

Date: 


\begin{abstract}
APPENDIX E
Initial Letter to Parents from Non-Separated or Non-Divorced Homes
\end{abstract}

August 30, 2002

Dear Parents,

I am currently involved in a study for a master's thesis at Cedarville University. Part of the study involves reviewing school records of students. I am looking for 40-60 families with children who are in Kindergarten - Sixth Grade who are willing to participate. Actual time involved would be minimal. Students would complete a written (or orally administered) questionnaire at the beginning of the study (early September) and again before Christmas break. School records such as attendance and academics would be reviewed. Confidentiality would be maintained.

The involvement includes permission for CCS staff to review records, to administer the questionnaire two times to the student, and to include general findings in the thesis while maintaining confidentiality and anonymity of students. If you are willing to allow your child to participate, please complete the attached form and return it to your child's teacher or to me. We would like to have the information returned in your child's folder for 9-3-02 if possible.

In the next few weeks, you will be contacted if you have volunteered and have been randomly selected to participate from all families who volunteered. Mr. James and the Executive Committee of Calvary Christian School have granted permission for this study to occur. If you would rather not participate, please check the appropriate information and return it to your child's teacher. Thank you in advance for returning the form!

Sincerely,

Cheryl Ellington

$6^{\text {th }}$ Grade Teacher/Upper Elementary Coordinator

Calvary Christian School 


\begin{abstract}
APPENDIX F
Permission Form for Children from Non-Separated or Non-Divorced Homes
\end{abstract}

Student Permission Form

(Please return in folder on 9-3-02)

Participant's (Child's) Name:

Child's Date of Birth:

Age/Grade:

Parent's Name and Phone Number:

Background:

My child has attended only Christian schools beginning in Kindergarten. My child has attended years at Christian schools and years in public schools. Other (Please explain.)

Please check the following to which you agree.

I willingly allow my child to participate in this study. I understand that the study involves reviewing school records.

I understand that anonymity and confidentiality will be maintained. I understand the project is part of a master's thesis. I understand that participants will be randomly selected from volunteers. I understand that my child may not be randomly selected for participation. I understand that I may withdraw my child from the study at any time. I release Calvary Christian School from any liability in relation to this study.

Parent's Signature and

Date:

If you would rather not participate in this study, please check the following and sign it: I decline the opportunity to participate in this study.

Parent's signature and date 


\section{APPENDIX G}

\section{Follow-Up Letter}

September 6, 2002

\section{Dear Parents,}

In your child's folder last Friday, a letter was sent from Mrs. Ellington. If you have already responded to this letter, THANK YOU SO MUCH!!! If you have not had the opportunity to send back your form, please do so this Monday if possible. I appreciate your help!

Sincerely,

Cheryl Ellington

$6^{\text {th }}$ Grade Teacher/Upper Elementary Coordinator Calvary Christian School 


\section{APPENDIX H \\ E-mail Enlisting Group Leader Help \\ E-mail to Elementary Teachers}

subject: help with thesis

I am currently working on my master's thesis for Cedarville University. My topic is the effects of divorce on kids and what Christian schools can do to support the kids. I have gained permission from the administration and Executive Board to proceed with the study. A major part of the study involves leading peer-support groups comprised of children from separated or divorced homes. The groups will meet after school on Tuesdays from 3:45-4:30 p.m. for 10-15 weeks. Hopefully, we will begin in September and conclude before Christmas Break. I have purchased curricula for the groups. Groups will have anywhere from 2-10 kids attending. Groups are divided into ages $\mathrm{K}-1^{\text {st }}$ grade, $2^{\text {nd }}-3^{\text {rd }}$ grade, and $4^{\text {th }}-6^{\text {th }}$ grade. I could really use some of your help to lead these groups if you are interested and willing to commit the time to them. At this point, we may have 10 groups or no groups. I simply do not know yet. Letters will be sent to all families, and we will wait for their responses to determine what groups will occur. Administration will award one CEU to teachers who assist. If you are interested, let me know. I'll be glad to give you more details.

Thanks.

Cheryl 


\section{APPENDIX I}

Contact Information for Children of Divorce Intervention Program

Dr. JoAnne Pedro-Carroll

Children's Institute Inc.

274 N. Goodman Street

Suite D103

Rochester, NY 14607

(716) 295-1000 (phone)

(716) 295-1090 (fax)

(877) 888-7647 (toll-free)

website: www.childrensinstitute.net

e-mail: jpcarroll@childrensinstitute.net

Evaluation tools:

Child-Rating Scale (CRS)

Teacher-Child Rating Scale (TCRS)

Parent Evaluation Form (PEF)

Group Leader Evaluation Form (GLEF)

Child Family Adjustment Scale (CFAS) 


\section{APPENDIX J}

\section{Researcher's Final Questionnaire for Students}

1. About how old were you when your parents separated or divorced?

2. How did your parents explain to you that they were separating or divorcing?

3. What has been the hardest thing for you about the separation or divorce?

4. Did you ever have the feeling that the separation or divorce might be partly your fault?

5. What is the most important thing you've learned from the separation or divorce?

6. What advice do you have for parents who are either thinking about separating or divorcing or have already done it?

7. What advice do you have for kids whose parents separate or divorce?

8. What advice do you have for teachers who are trying to help kids whose parents have separated or divorced?

9. Does your parents' separation or divorce still affect you? Explain. 


\section{APPENDIX K}

\section{Final Group Discussion Questions}

My dad is doing something special without me, and I feel really left out. What can I do?

I can't talk to my parents about the divorce, and they told me not to talk to anyone else about it either. What can I do?

I've been separated from my brothers and sisters because of the divorce, and I really miss them. What can I do?

I just found out that the parents of one of my good friends are getting a divorce. How can I help my friend?

Thanksgiving is almost here. I will only see one of my parents. What can I do to let both parents know I love them?

Once our group quits meeting every Tuesday, if I have a problem I want to talk about, what should I do?

Mom wants me to take her side against Dad. Dad wants me to take his side against Mom. I don't want to take sides with anyone. What can I do?

It's hard for me to keep track of my school work because I go back and forth between two homes. How can I get organized so I won't leave something at the wrong place?

Sometimes I feel really sad. Is this o.k., and what can I do to feel better?

I feel pretty well adjusted to the divorce of my parents. Should I feel guilty because I don't seem to struggle with problems other kids have because their parents are divorced?

Why did God let my parents become separated or divorced?

Because my parents were separated or divorced, does that mean that when I grow up and get married that I will also probably get separated or divorced?

When I grow up, how can I be sure that I am marrying the right person so we won't end up divorced?

Did God make a mistake with me by letting me live with divorced parents?

I have heard that I can be a stronger person because I have lived in a divorced home. How can this be? 
I have a hard time getting my homework done. What can I do?

Sometimes I feel like my parents would rather not have me around. This really hurts. What can I do?

We don't have enough money to do fun things. What can I do?

My parents seem to be angry a lot. This bothers me. Is there anything I can do?

I have a hard time dealing with my own anger. Sometimes I take it out on people I'm not really mad at. What can I do?

I have a hard time getting my chores done. Then I get in trouble. What can I do? 


\section{APPENDIX L}

\section{Final Teacher Questionnaire}

\section{Teacher Questionnaire}

Thank you for sharing your valuable time with me. This is the final piece of information for which I will ask. Please provide answers as you are able. Use the back of the questionnaire if needed. Please return the form in my box in the teachers lounge. Names are optional.

1. About how long have you been teaching? years in Christian schools years in public schools other (please explain) total years teaching

2. Are you usually aware when students in your class come from separated or divorced homes? (How do you gain this information? Would it help you to know which students are from separated or divorced homes?)

3. In your experience as a teacher, has family separation or divorce affected students in the classroom setting? If so, please explain what you have observed.

4. In your experience as a teacher, has family separation or divorce affected your communication with parents? If so, please explain.

5. What strategies have you used to help students from separated or divorced homes in your classroom?

6. What advice do you have for other teachers who are working with students experiencing family separation or divorce? 


\section{APPENDIX M \\ Final Parent Questionnaire \\ Parent Information and Feedback \\ (Feel free to use the back if you need more room.)}

Name:

Date:

1. From what you can tell, what has your child's basic attitude been regarding attending the support groups?

2. Has your child shared anything he/she has learned or experienced in the groups? If so, please give an example.

3. Have you noticed any changes, either positive or negative, in your child in association with the groups? If so, please explain.

4. What could classroom teachers do to better assist you and your child in regards to separation or divorce?

5. What could CCS do to better assist you and your child in regards to separation or divorce?

6. In your opinion, was the group experience beneficial for your child? Please explain. 


\title{
APPENDIX N
}

\author{
Final Letter to Parents
}

November 19, 2002

Dear Parents,

It has been an absolute delight to work with your children these past few weeks. Each one has contributed significantly to our peer support groups! We have just two meetings remaining: November 26 and December 3. We will celebrate with refreshments on December 3 .

Enclosed is a questionnaire that would greatly assist me. Please complete it and return it via your child as soon as it is ready. (They have been promised a candy bar in exchange for the returned information.) Your feedback will help us determine if support groups should be offered in the future and will help to identify other ways we can assist you.

Thank you so much for the opportunity to include your children in our support groups. They have been a blessing!

Sincerely,

Mrs. Ellington

Mrs. McQueen

Miss Owens

Mrs. O'Dwyer 


\section{APPENDIX O \\ Random Selection Letter}

\section{Dear Parent,}

Your child was randomly selected as a participant for my thesis study. A questionnaire regarding feelings about school and friends will be given to him this week and again in December. The questionnaire takes about five minutes to answer and will be completed at school.

Thank you for allowing your child to participate.

Sincerely,

Mrs. Ellington 


\section{APPENDIX P \\ Letter Giving Details of Peer-Support Groups to Parents}

\section{Dear Parents,}

Thank you for allowing your child to be involved in our support groups. The first meeting will be this coming Tuesday, September 23 from 3:45-4:30 p.m. If students are staying after school, they should simply go to the cafeteria right after school. They will have about 45 minutes to work on homework etc. Although this is the Extended Child Care room, there is no charge for students participating in our groups. We will come get the students between 3:30 and 3:45 and move to our locations. The children in K-3 ${ }^{\text {rd }}$ grade will meet in Mrs. McQueen's room and will be led by Mrs. McQueen and Mrs. O'Dwyer. The $4^{\text {th }}-6^{\text {th }}$ grade students will meet in Miss Owens' room and will be led by Mrs. Ellington and Miss Owens. Students will go to ECC room (cafeteria) following groups and may be picked up at that location. Once again, there will be no charge for our students as long as they are picked up by 4:45 p.m.

The following are the Tuesday dates of our group meetings:
$9 / 24$
$10 / 1$
$10 / 8$
$10 / 15$
$10 / 22$
$10 / 29$
$11 / 5$
$11 / 12$
$11 / 19$
$11 / 26$
$12 / 3$
$12 / 10$

There is a possibility we will conclude before December 10, but we will let you know closer to December.

Parents, if you could take a few minutes and fill out the questionnaire enclosed, I would so appreciate it. Simply return it in the confidential envelope in your child's folder on Monday.

We are excited about working with your children! We already love them. Thank you SO MUCH for this opportunity.

Sincerely,

Mrs. Ellington 


\section{REFERENCES}

Ahrons, C. (1994). The good divorce. New York: Harper Collins Publishers.

Albee, G., Gullotta, T. (1997). Primary prevention works: Issues in children's and families' lives: Volume 6. Thousand Oaks, California: Sage Publications.

Alpert-Gillis, L., Pedro-Carroll, J., Cowen, E. (1998). The children of divorce intervention program: Development, implementation, and evaluation of a program for young urban children. Journal of Consulting and Clinical Psychology, 57, (5), 583-589.

Amato, P. (2001). Children of divorce in the 1990s: An update of the Amato and Keith (1991) meta-analysis. Journal of Family Psychology, 15, (3), 355-370.

Amato, P., Keith, B. (1991). Parental divorce and the well-being of children: a metaanalysis. Psychological Bulletin, 110, (1), 26-46.

Barber, N. (2000). Why parents matter: Parental involvement and child outcomes. Westport, Connecticut: Bergin and Garvey.

Barna, G. (1999). Christians are more likely to experience divorce than are non-christians. The Barna Report. October-December, 9-12.

Barr, D. (1982). Caught in the crossfire: Children of divorce. Grand Rapids, Michigan: Zondervan Publishing House.

Belli, M., Krantzler, M. (1988). The complete guide for men and women: Divorcing. New York: St. Martin's Press.

Benedek, E. (1998). How to help your child overcome your divorce. New York: New Market Press.

Berry, D. (1988). The divorce recovery sourcebook. Los Angeles: Lowell House. 
Biblarz, T. (2000). Family structures and children's success: A comparison of widowed and divorced single-mother families. Journal of Marriage and the Family. 62, (2), May, 533.

Bode, J., Mack, S. (2001). For better or worse: A guide to surviving divorce for preteens and their families. New York: Simon and Schuster Books.

Brodkin, A., Coleman, M. (1995). Support for children of divorce: How teachers can help with healing. Instructor. Jan.-Feb., 30-31.

Carlile, C. (1991, summer). Children of divorce - How teachers can ease the pain. Childhood Education, 232-234.

Coontz, S. (1997). Divorcing reality. The Nation. Nov. 17, 21.

Craig, G. (1996). Human Development. Upper Saddle River, NJ: Prentice Hall.

Diamond, S. (1985). Helping children of divorce: A handbook for parents and teachers. New York: Schocken Books.

Driedger, S. (1998). After divorce. Macleans. April 20, p.39.

Emery, R. (1999). Marriage, divorce, and children's adjustment: Second edition. Thousand Oaks, California: Sage Publications.

Engel, M., Gould, D. (1992). The divorce decisions workbook.. New York: McGrawHill Inc.

Fassel, D. (1991). Growing up divorced: A road to healing for adult children of divorce. New York: Pocket Books.

Furstenberg, Jr. F., Cherlin, A. (1991). Divided families: What happens to children when parents part. Cambridge, Massachusetts: Harvard University Press.

Glesne, C. (1999). Becoming qualitative researchers. New York: Longman. 
Goldentyer, D. (1998). Divorce; Preteen pressures. Austin, TX: Raintree Steck-vaughn Publishers.

Hargreaves, M.B. (1991). Learning under stress: Children of single parents and the schools. Metuchen, New Jersey: Women's Action Alliance and The Scarecrow Press, Inc.

Hart, A. (1996). Children of divorce: What to expect, how to help. Waco, Texas: Word Books.

Hetherington, E., Bridges, M., Insabella, G. (1998). What matters? What doesn't? Five perspectives on the association between marital transitions and children's adjustment. American Psychologist, 15, (2), 167-184.

Hetherington, E., Kelly, J. (2002). For better or worse: Divorce reconsidered. New York: W.W. Norton \& Company.

Jeynes, W. (1999). Effects of remarriage following divorce on the academic achievement of children. Journal of Youth and Adolescence. 28 (3). 385-393.

Jonsson, J., Gahler, M. (1997). Family dissolution, family reconstitution, and children's educations careers: Recent evidence for Sweden. Demography. 34, (2), Washington, 277-293.

Kimball, G. (1994). How to survive your parents' divorce: Kids' advice to kids. Chico, California: Equality Press.

Krementz, J. (1984). How it feels when parents divorce. New York: Alfred Knopf, Inc.

Lang, G., Heiss, G. (1998). A practical guide to research methods. Lanham, Maryland: University Press of America.

Lansky, V. (2000). Vicky Lansky's divorce book for parents: Helping your children 
cope with divorce and its aftermath. Minnetonka, Minnesota: Book Peddlers.

Levine, B. (1995). Divorce: Young people caught in the middle. Springfield, New Jersey: Enslow Publishers.

Lewis, J., Sammons, W. (1999). Don't divorce your kids: Children and their parents talk about divorce. Lincolnwood (Chicago), Illinois: Contemporary Books.

Lipnickey, S. (2001). Between two homes. American School Board Journal, 46-47, 55.

Manning, S. (1991). Children of divorce. Scholastic Update. September 6, 13-15.

Martinez, C., Forgatch, M. (2002). Adjusting to change: Linking family structure transitions with parenting and boys' adjustment. Journal of Family Psychology. 16, (2), 107-117.

Maynard, J. (1998). The truth about kids and divorce. Ladies' Home Journal, May. McKay, M. (1999). The divorce book: A practical and compassionate guide. Oakland, California: New Harbinger Publications.

McLaughlin, L. (2002, Jan 28). Does divorce hurt kids? Time, 159, (4), 40.

Miller, P., Ryan, P., Morrison, W. (1999). Practical strategies for helping children of divorce in today's classroom. Childhood Education, 75, (5), 285-289.

Neuman, G. (1999). The divorced parents' handbook. Parents. September. 153-156.

Neuman, G., Romanowski, P. (1998). Helping your kids cope with divorce the sandcastles way. New York: Time Books.

Nickman, S. (1986). When mom and dad divorce. New York: Julian Messner.

Pedro-Carroll, J. (1994). Children of divorce intervention program: A procedures manual for conducting support groups with fourth - sixth grade children. Rochester, New York: Primary Mental Health Project, Inc. 
Pedro-Carroll, J., Alpert-Gillis, L. (1993). Children of divorce intervention program: A procedures manual for conducting support groups with kindergarten and first grade children. Rochester, New York: Primary Mental Health Project, Inc.

Pedro-Carroll, J., Alpert-Gillis, L., Sterling, S. (1997). Children of divorce intervention program: A procedures manual for conducting support groups with second and third grade children. Rochester, New York: Primary Mental Health Project, Inc.

Pedro-Carroll, J., Sutton, S., Wyman, P. (1999). A two-year follow- up evaluation of a preventive intervention for young children of divorce. The School Psychology Review, 28,(3), 467-476.

Rentmeester, M. (1997). Splintered families. Seventeen. 56, December, 163-167.

Richardson, C., Rosen, L. (1999). School-based interventions for children of divorce. Professional School Counseling. 3:1. October. 21-26.

Richmond, G. (1988). The divorce decision. Dallas, Texas: Word Publishing. Rothchild, G. (1999). Dear mom and dad: What kids of divorce really want to say to their parents. New York: Pocket Books.

Sammons, W., Lewis, J. (2000, September). What schools are doing to help the children of divorce. Young Children, 64-65.

Shinoda, K. (2001). Children of divorce: The impact on classroom behavior. (Master's Thesis, Biola University, 2001). Educational Resources Info rmation Center (ERIC, ED456346).

Simons, R., Lin, K., Gordon, L, Conger, R., Lorenz, F. Explaining the higher incidence of adjustment problems among children of divorce compared with those in two- 
parent families. (1999, November). Journal of Marriage and the Family, 61, 1020-1033.

Slavin, R.E. (1986). Best-evidence synthesis: an alternative to meta-analytic and traditional reviews. Educational Researcher, 15, (9), 5-11.

Spiesman, J. (1999). The role of the school when a family dissolves: Perceptions of parents, educators, and social service professionals. (Doctoral Dissertation, Youngstown State University, 1999). Ohio Link. YSU 996755318.

Teyber, E. (2001). Helping children cope with divorce. San Francisco, California: JosseyBass.

Thompson, R., Amato, P. (1999). The Postdivorce family: Children, parenting, and society. Thousand Oaks, California: Sage Publications.

Wadsby, M., Svedin, C. (1996). Academic achievement in children of divorce. Journal of School Psychology,34, (4), 325-336.

Wallerstein, J., Lewis, M. L., Blakeslee, S. (1995). Second chances: Men, women, and children a decade after divorce. New York: Ticknor and Fields.

Wallerstein, J., Kelly, J. (1980). Surviving the break-up. New York: Basic Books. Wallerstein, J., Lewis, M. L., Blakeslee, S. (2000). The unexpected legacy of divorce: A 25-year landmark study. New York: Hyperion.

Weyburne, D. (1999). What to tell the kids about your divorce. Oakland, California: New Harbinger Publications.

Wolchik, S., Karoly, P. (1988). Children of divorce: Empirical perspectives on adjustment. New York: Gardner Press, Inc.

Wolf, A. (1998). Why did you have to get a divorce and when can I get a hamster? 
New York: The Noonday Press.

Zinsmeister, K. (1996, Sept/Oct). Family meltdown in the classroom. The American Enterprise, 7, (5), 42. 


\section{VITA}

Cheryl Ann Ellington grew up in Cincinnati, Ohio. Her parents, Verne and Katie Sprunger, were respectively an aeronautical engineer and a Christian schoolteacher before retiring. She has one sister, Sandy Nunn, who is currently a lawyer in Cincinnati.

Cheryl came to receive Jesus as her personal Savior at the age of three. She was baptized at age seven. As a child, Cheryl loved school, animals, and piano. These continue to be key factors in her life. Her relationship with Jesus Christ and the church have always been important priorities. Today she attends Calvary Baptist Church where her husband, Dave, is the worship pastor. She is involved in the church as an accompanist.

Cheryl graduated from Landmark Christian School in 1976. She attended Cedarville University and majored in elementary education with a specialization in music education. It was at Cedarville where she met her husband, Dave Ellington, who was majoring in music ministry. Upon graduating in 1980, they were married.

Together, Cheryl and Dave have lived and ministered in Cincinnati, Ohio, Rochester, New York, Des Moines, Iowa, Liberal, Kansas, West Palm Beach, Florida, and Covington, Kentucky. Cheryl has taught full-time in Christian schools in kindergarten, third grade, and sixth grade. One year involved teaching first grade in a public school. Years of full-time teaching experience number fifteen. When sons Matt and Jon were born, the new priority became staying home to care for them. During this 
seven year period, Cheryl stayed involved in education through substitute teaching. She is currently in her tenth year of teaching sixth grade at Calvary Christian School in Covington, Kentucky.

Cedarville University initiated a graduate program in the year 2000, twenty years after Cheryl's graduation. While the number of years since attending college was intimidating, Cheryl began her master's work in education and completed it in May, 2003.

Her family (including the Sheltie), sixth grade class, colleagues, church, and work as an accompanist fill her life with purpose and joy.

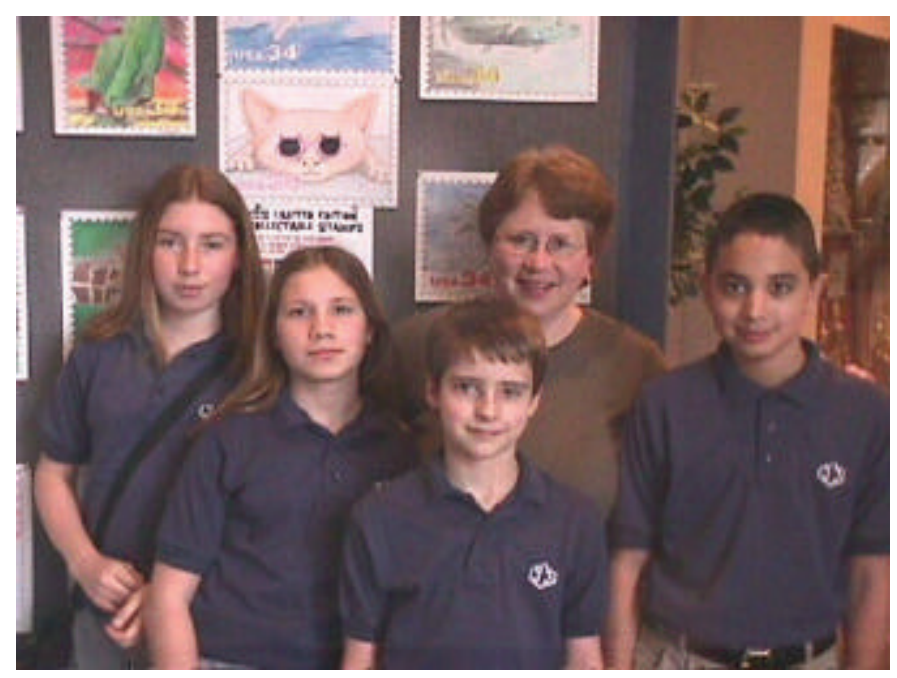

Contact the author at: cellington@calvarychristianky.org OR dellington@,fuse.net 